Report No. BMI-1244

C -25 Metallurgy and Ceramics (M-3679, 20th Ed., Rev. 1)

Contract No. W-7405-eng-92

\title{
THE CLADDING OF DELTA-PHASE ZIRCONIUM HYDRIDE
}

by

Stan J. Paprock

Edwin S. Hodge

Charles B. Boyer

Ca

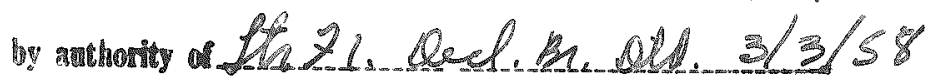

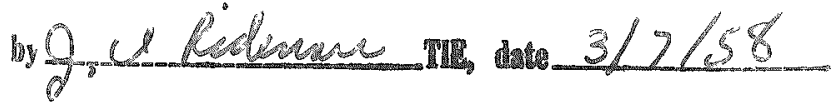

December 27,1957

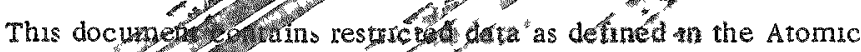

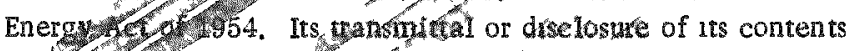
in ahy maner to an uratathwized personus prohibired.

BAT TELLE MEMORIAL INSTITUTE 505 King Avenue

- Columbus 1, Ohio 


\section{DISCLAIMER}

This report was prepared as an account of work sponsored by an agency of the United States Government. Neither the United States Government nor any agency Thereof, nor any of their employees, makes any warranty, express or implied, or assumes any legal liability or responsibility for the accuracy, completeness, or usefulness of any information, apparatus, product, or process disclosed, or represents that its use would not infringe privately owned rights. Reference herein to any specific commercial product, process, or service by trade name, trademark, manufacturer, or otherwise does not necessarily constitute or imply its endorsement, recommendation, or favoring by the United States Government or any agency thereof. The views and opinions of authors expressed herein do not necessarily state or reflect those of the United States Government or any agency thereof. 


\section{DISCLAIMER}

Portions of this document may be illegible in electronic image products. Images are produced from the best available original document. 
3 and 4

ABSTRACT • . . . . . . . . . . . . . . . . . 5

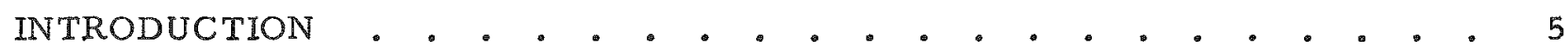

EXPERIMENTAL TEST PROCEDURES . . . . • . • . . . • . . 66

Pressure-Bonding Process and Equipment . . . . . . . . . 6

Materials . . . . . . . . . . . . . . . . . . . 11

Preparation of Specimens for Pressure Bonding . . . . . . . . . 11

Fabrication of Cans for Pressure Bonding . . . . . . . . . . . 12

Cleaning Techniques . . . . . . . . . . . . . . . . . 13

Assembly and Evacuation of Compacts for Pressure Bonding. • . . . 13

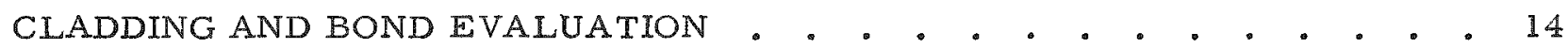

Evaluation Procedures for Clad Specimens . . . • . . . . . . 14

Preliminary Bonding Studies . . . . . . . . . . . . 15

Thermal-Cycling Tests . . . . . . . . . . . . . . 26

Hydrogen-Retention Studies . . . . . . . . . . . . . . . 27

General Conclusion From the Preliminary Bonding Studies . . . . . 31

DEVELOPMENT STUDIES FOR DIRECT CLADDING OF SOLID

DELTA-PHASE ZIR CONIUM HYDRIDE WITH STAINLESS STEEL • • • . 31

Flat-Plate Specimens . . . . . . . . . . . . . . . 32

Direct Cladding of Powder-Metallurgy Zirconium Hydride

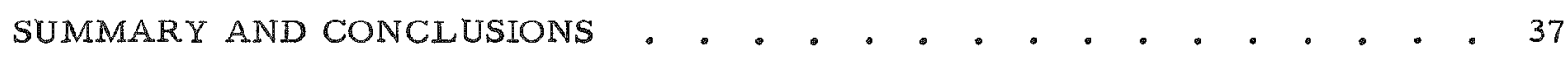




\title{
THE CLADDING OF DELTA-PHASE ZIRCONIUM HYDRIDE
}

\author{
Stan J. Paprocki, Edwin S. Hodge, and Charles B. Boyer
}

\begin{abstract}
A study has been made of the cladding of solid and powdered deliaphase zirconium hydride in both rod and flat shopes with stainless steel. The program included investigations of metallurgical bonding, both with and without the use of metallic barrier materials. Types 304 and 34.7 stainless steel were used for cladding material. The interme diate barrier-layer materials used were miobium, molybdenum, a combination of copper and molybdenum, and a combination of copper and niobium.
\end{abstract}

The pressure-bonding techniques, involving the use of gas pressure at elevated temperatures, was employed in this study. Variable times and temperatures with a constant pressure of 10,000 psi were utilized to produce bonding.

In this study, the best results were achieved in cladding delta-phase zirconium hydride directly with Types 304 or 347 stainless steel. Good bonds were obiained by pressure bonding at $1600 \mathrm{~F}$ for 3 or $4 \mathrm{hr}$ subsequent to pressure bonding at $1900 \mathrm{~F}$ for 1 to $2 \mathrm{hr}$ at a pressure of 10,000 psi. Partial bonding was achieved between niobium and zirconium hydride and molybdenum and zirconium hydride.

\section{INTRODUCTION}

The initial reference design for the GCRE imposed relatively severe limitations on the core size and fuel loading. A survey of suitable moderator materials was conducted and metallic hydrides were found most applicable. The delta-phase zirconium hydride was chosen as the reference hydride.

The zirconium hydride had to be clad with a material that possesses hightemperature properties to structurally re-enforce the hydride and to protect it from attack by the reactor coolant. In addition, a metallurgical bond or a bond nearly equivalent in heat-transfer characteristics had to be formed between the cladding and hydride to prevent excessive temperatures from occurring in the hydride, which would result in hydrogen dissociation. The bond also had to possess resistance to thermal cycling, as extensive thermal cycling of the material was anticipated.

An investigation was directed toward the cladding of delta-phase zirconium hydride to give a finished moderator element which would be capable of withstanding the proposed GCRE operating conditions. The program included the cladding of both solid and powdered zirconium hydride in both rod and flat shapes. The investigations included metallurgical bonding, both with and without the use of metallic barrier materials.

Types 304 and 347 stainless steel were used for cladding direct or with barrier layers of molybdenum, niobium, a combination of copper and niobium, and a combination of copper and molybdenum.

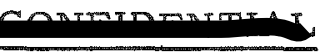


The technique of pressure bonding, which is more adaptable to the cladding of brittle materials than conventional methods, was utilized in the cladding of the zirconium hydrides.

\section{EXPERIMENTAL TEST PROCEDURES}

\section{Pressure-Bonding Process and Equipment}

The pressure-bonding process employed in this cladding study makes use of a gas pressure at elevated temperatures to bring about intimate contact of the cladding and core to achieve a bond between the two.

This technique was utilized because of certain unique advantages it has for the cladding of brittle materials over conventional bonding processes. There is no significant reduction or deformation of the components and the pressure is uniform over the entire specimen.

In general, the pressure-bonding process involves the fabrication of the cladding and core components to approximately final size. The se components are cleaned and assembled into a can which is evacuated and sealed. The canned assembly is then loaded into an autoclave where helium gas pressure at elevated temperatures is applied for a certain length of time. At the end of this time, the canned bonded element is taken from the autoclave. The assembly technique used in preparing rod-type elements for pressure bonding is shown in Figures 1 and 2.

A high-pressure autoclave acquired from the Autoclave Engineering Company and modified by Battelle personnel was used in conducting this study. The autoclave body, machined from a Type 410 stainless steel forging, is $61-3 / 4 \mathrm{in}$. long with a $9-$ in. ID and a 13.650-in. OD. The body is open on both ends and a tight seal is maintained against leakage of helium gas by employing top and bottom heads which utilize a modified Bridgeman seal. The unit is designed to operate at a pressure of 10,000 psi with a wall temperature of $700 \mathrm{~F}$. Figure 3 shows a sectional view of the autoclave unit.

A resistance internal heater is incorporated in the center of the autoclave. Fiberfrax fiber insulation packed around the heater prevents rapid heating of the autoclave wall. Two thermocouples are employed to control the temperature inside the autoclave, one placed next to the windings of the furnace, and the other next to the specimen. Temperatures of $1925 \mathrm{~F}$ at 10,000 psi have been attained with the outside wall of the autoclave not exceeding $250 \mathrm{~F}$. This temperature is well within the design wall temperature of $700 \mathrm{~F}$.

The high-pressure autoclave unit is shown in Figure 4.

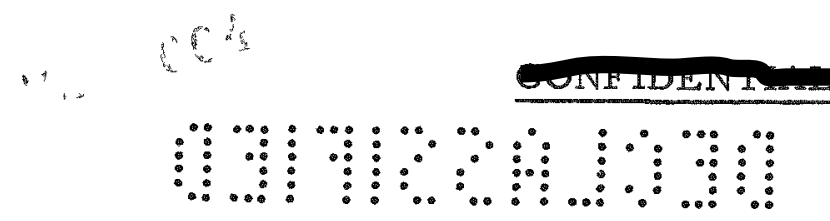



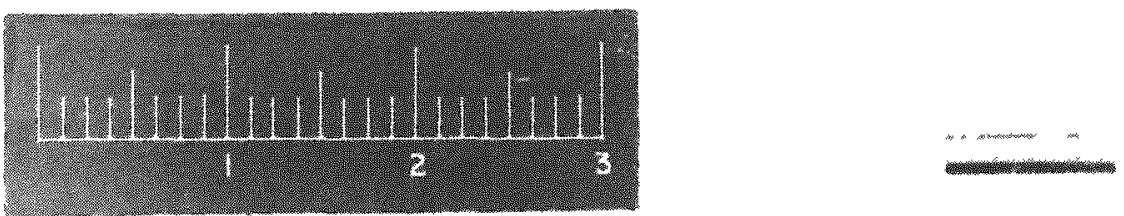

N41631

FIGURE 1. ASSEMBLY TECHNIQUE FOR THE ROD-TYPE SPECIMENS 


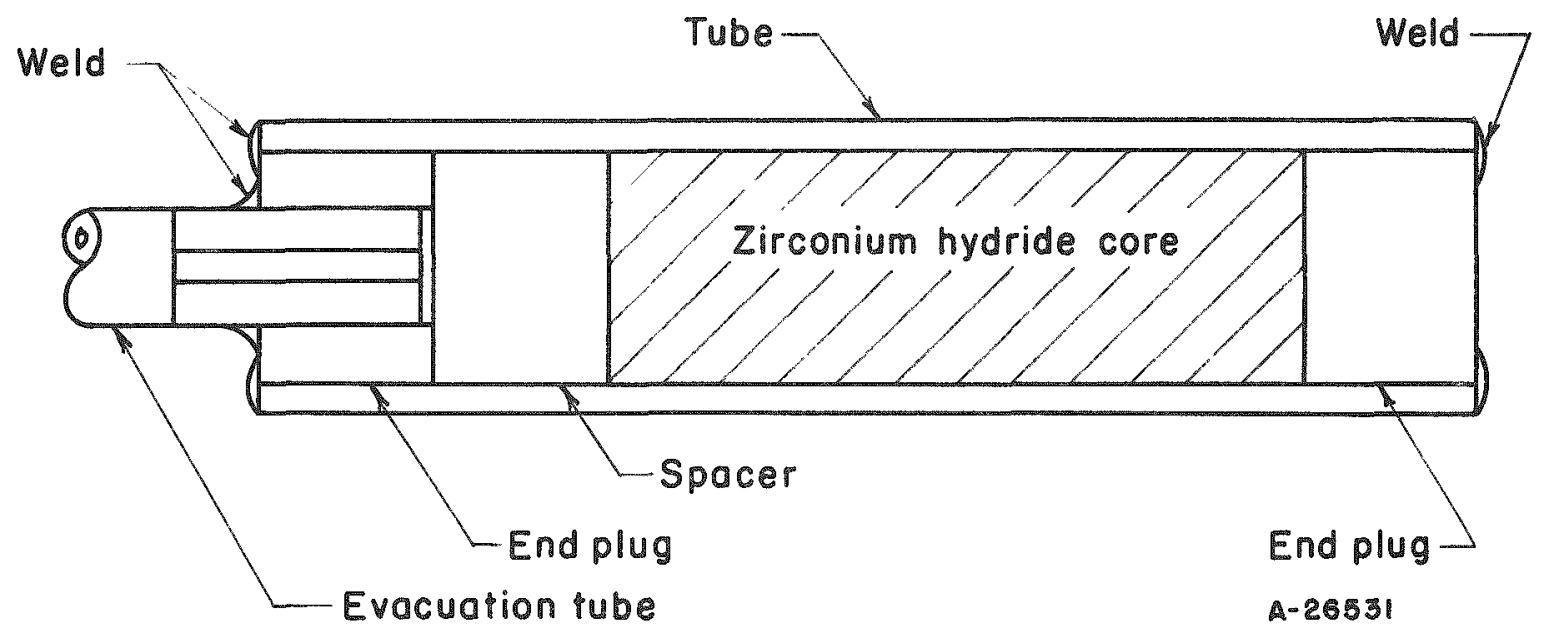

FIGURE 2. SECTIONAL VIEW OF A ROD SPECIMEN

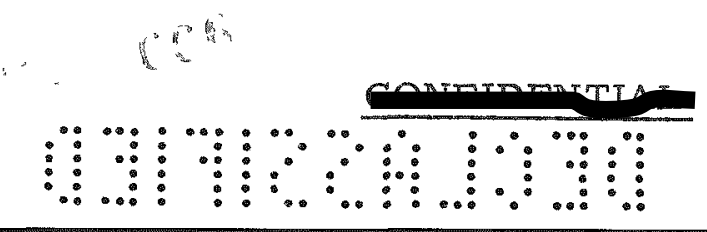




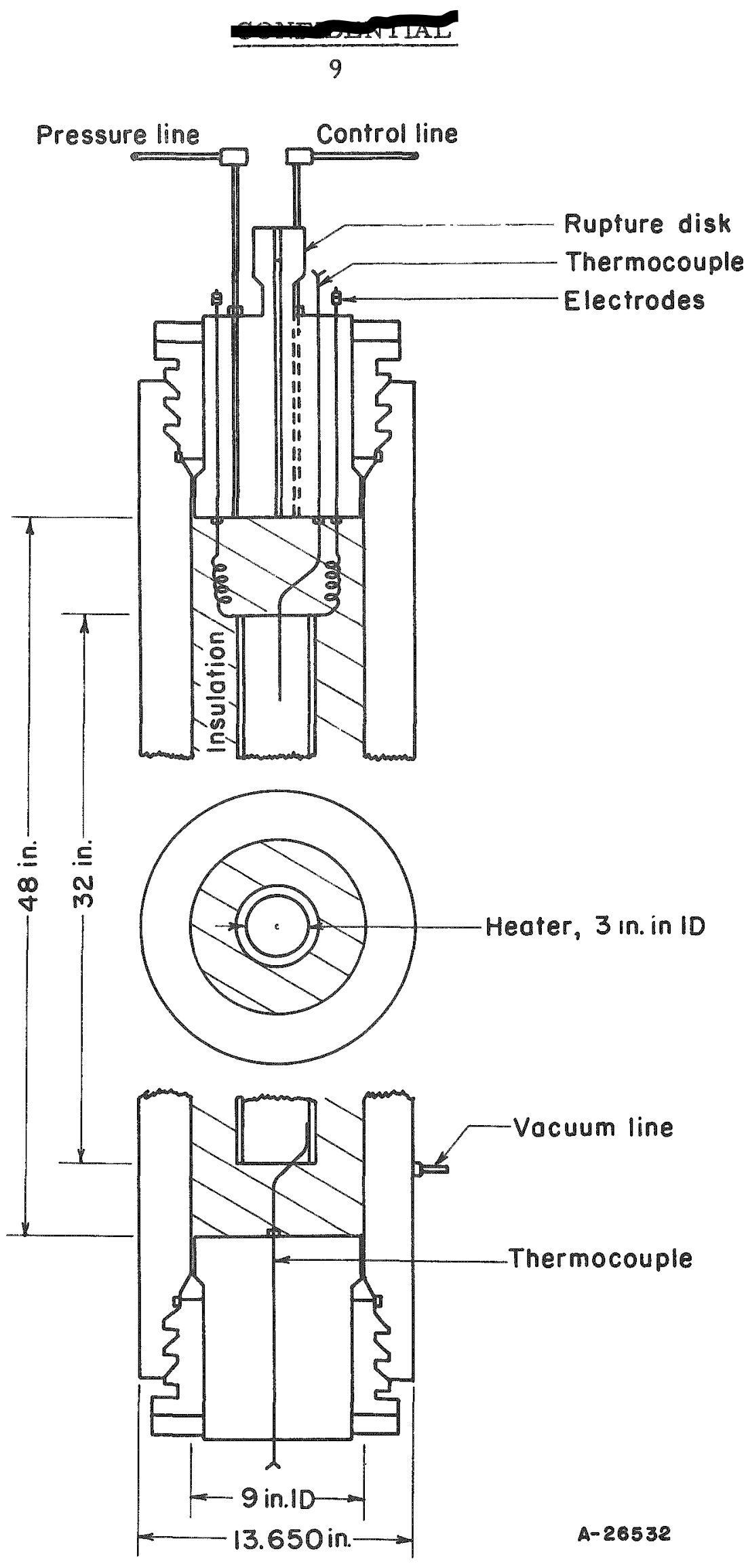

FIGURE 3. SECTIONAL VIEW OF THE HIGH-PRESSURE AUTOCLAVE

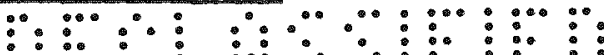




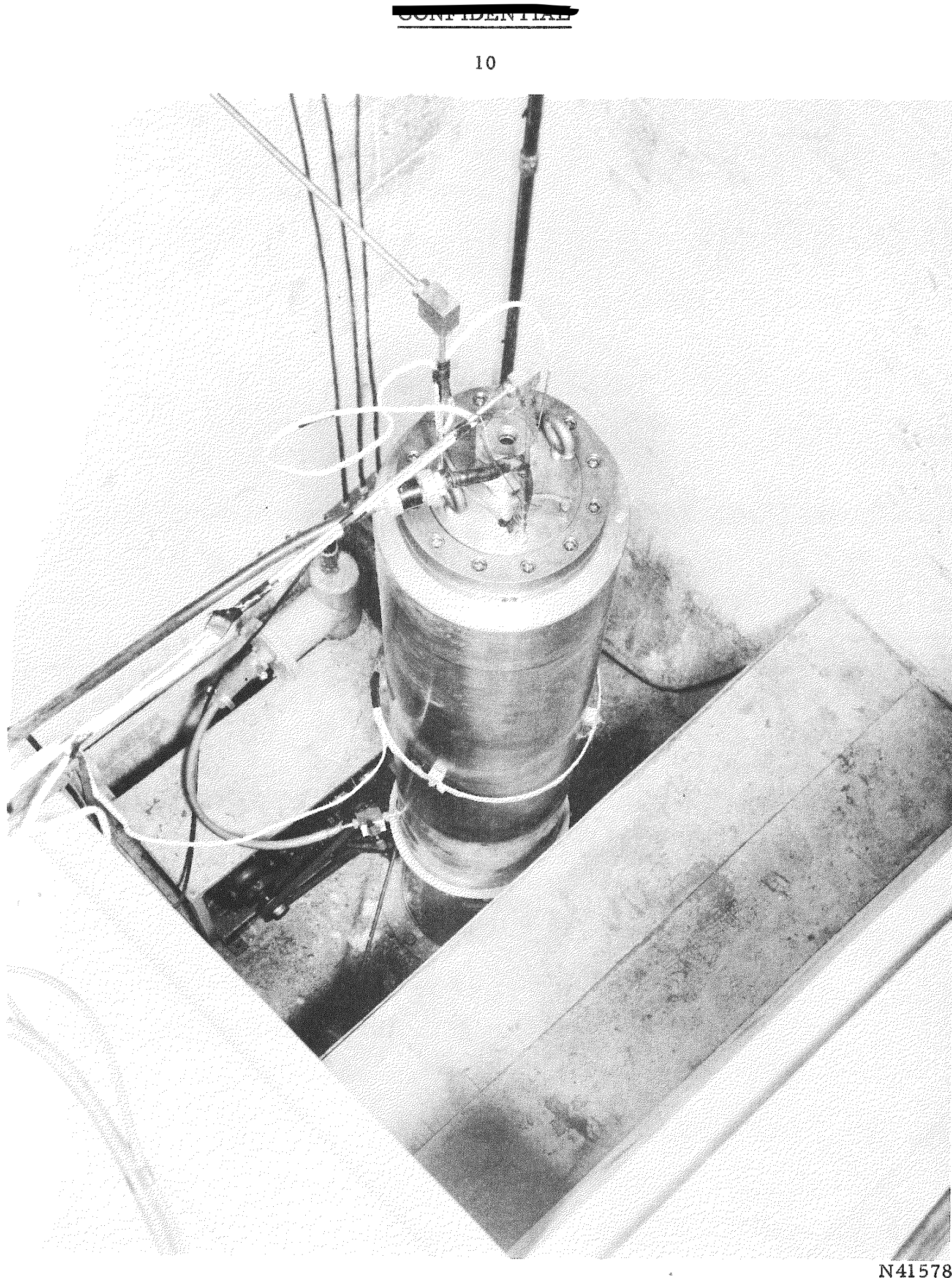

FIGURE 4. THE HIGH-PRESSURE AUTOCLAVE UNIT

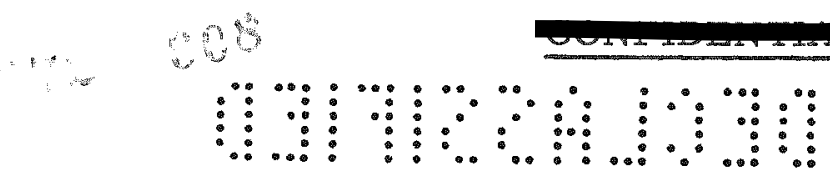


The solid delta-phase zirconium hydride specimens were prepared at Battelle using reactor-grade zirconium bar stock that was machined to size. The method for preparing this material is described in BMI-1243. The composition of the zirconium hydride specimens employed in this study varied from $Z_{r} H_{1.5}$ to $1.9\left(N_{H}=5.5-7.0\right)$.

The zirconium hydride power, used to produce cores, was obtained from Metal Hydrides, Incorporated. The composition is presented below:

\begin{tabular}{lllllllllll}
\multicolumn{10}{c}{ Analysis, w/o } \\
\hline$\frac{\mathrm{Al}}{0.277}$ & $\frac{\mathrm{Ca}}{0.01}$ & $\frac{\mathrm{Cl}}{0.003}$ & $\frac{\mathrm{H}_{2}}{2.08}$ & $\frac{\mathrm{Fe}}{0.015}$ & $\frac{\mathrm{Mg}}{0.05}$ & $\frac{\mathrm{N}_{2}}{0.30}$ & $\frac{\mathrm{Si}}{0.032}$ & $\frac{\mathrm{Zr}}{96.5}$ & $\frac{\mathrm{Ti}}{0.075}$
\end{tabular}

This zirconium hydride powder was also decomposed under controlled conditions at Battelle to produce $\mathrm{ZrH}_{\mathrm{L}} .4$ to 1.6 powder from which cores were also prepared.

I'ype 347 and Type 304 stainless steels were selected as the potential cladding materials on the basis of their corrosion resistance to the nitrogen-plus-water vapor coolant.

The 0.005-in.-thick niobium and molybdenum sheet for use as barrier-layer materials were both obtained from the Fansteel Metallurgical Corporation.

The phosphorized copper used as an intermediate barrier-layer material was obtained from the American Brass Company. This material was cold rolled from a $0.647-\mathrm{in}$. -thick sheet to a thickness of $0.005 \mathrm{in}$.

\section{Preparation of Specimens for Pressure Bonding}

It was determined in the early phase of this cladding study that in order to obtain satisfactory results during pressure bonding, care had to be observed in the preparation and fabrication of the specimens to obtain adequate dimensional control between the components.

During the preparation of solid zirconium hydride uneven growth of the specimen occurred, and it was difficult to predetermine actual size of the hydrided specimen or have any dimensional control over the finished specimens. A technique was developed for limited machining of the solid delta-phase zirconium hydride specimens, and, as a result, it was possible to more closely control the core-to-cladding tolerances. All rod specimens were machined on the diameter and both ends. The flat-plate specimens used in this cladding study were all produced with the cores restrained inside of a stainless steel frame. These restrained zirconium hydrides were machined on the top and bottom to various thicknesses to obtain flat surfaces.

In the early stages of this study, all emphasis was on solid hydride specimens and these were used exclusively. Later, excellent success was encountered with hydride specimens produced by powder-metallurgy techniques and pressed-powder cores were utilized. 


\section{2}

Powdered zirconium hydride cores were fabricated by cold pressing minus 325-mesh $\mathrm{ZrH}_{2}$ and $\mathrm{ZrH}_{1.4}$ to 1.6 powder at 60 tsi. Rod specimens prepared in this manner were $1 / 2 \mathrm{in.}$ in diameier by $1 / 2 \mathrm{in}$. in length. Tlat-plate specimens 1 by 1 by $0.250 \mathrm{in}$. were also produced by this technique. These specimens were generally a few thousandths of an inch oversize and were hand ground to size using 600-grit paper.

The main effort in the preparation of powder-metallurgy zirconium hydride cores was to improve the green density. The effects of various die lubricants were investigated. Lubricants which were evaluated included Ceremul "C", paraffin in ether, paraffin in benzene, camphor in ether, stearic acid, mineral oil, zinc stearate, oleic acid, benzoic acid, MoSi2, mica, Oildag, vermiculite, Dag 217, and camphor in alcohol. The most effective of the me materials was Ceremul "C". Densities of 4.6 to $4.7 \mathrm{~g}$ per $\mathrm{cm}^{3}$ were obtained at 60 tsi using this lubricant.

\section{Fabrication of Cans for Pressure Bonding}

The flat-plate specimens required an outer protective pressure-tight can to envelope the components for pressure bonding. Different styles of cans were designed to suit desired conditions. The swastika design, an example of which is shown in Figure 5, appeared to give the best results for this application. Type 304 stainless stecl sheet material approximately $0.018 \mathrm{in}$. thick for the sides and $0.080 \mathrm{in}$. thick for the ond plugs was used for these cans.

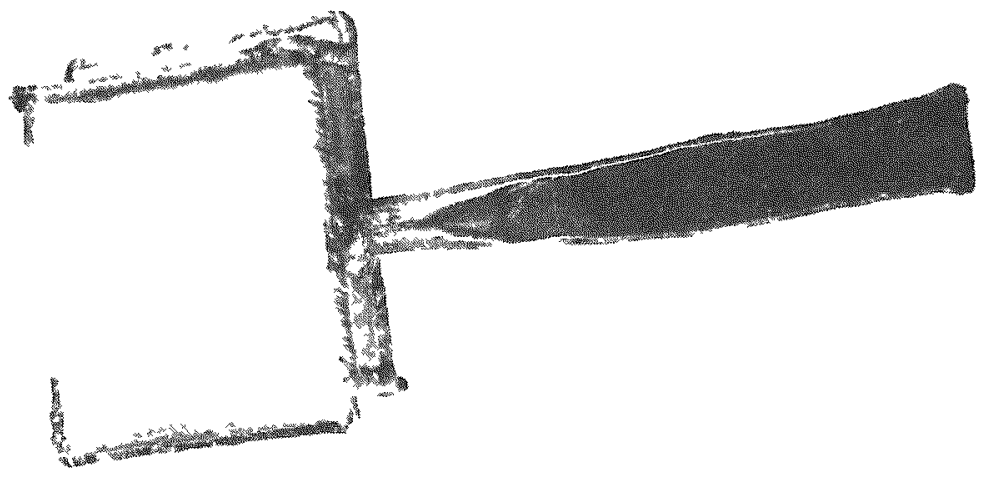

RM8121

\section{FIGURE 5. SWASTIKA PACK AFTER PRESSURE BONDING}

Cans were fabricated by shearing the side plates and end plugs to size, drilling one end plug to accept the evacuation tube, and forming a 90-deg flange 3/16 in. wide on the side plates, as shown in Figure 5. All parts were degreased, assembled, and clamped to a machined form block preparatory to welding. After Heliarc welding the side plates, the evacuation tube, and one end plug into place, the form block was removed and the specimen was preassembled into the can to assure proper fit. The specimen was then removed and the can and end plug were recleaned preparatory for final assembly.

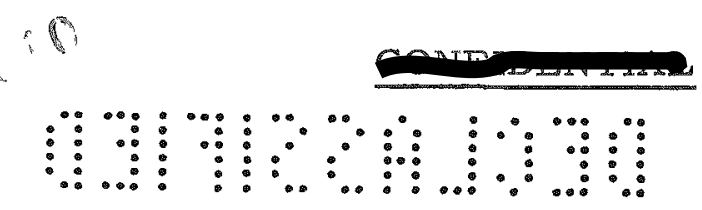




\section{Cleaning Techniques}

The pressure-bonding process requires careful surface preparation to effect bonding. The minimum amount of surface deformation produced by pressure bonding is insufficient to break up any surface films present on the components; therefore, clean surfaces are necessary to minimize these films.

After machining and just before assembling, the stainless steel components, including the assembled tubes and cans, were scrubbed with steel wool in acetone and placed in a hot trichlorethylene bath for degreasing. After degreasing, the stainless steel components were washed in cold Alconox solution, rinsed in cold running water, and subjected to a series of washings and rinses as follows: $180 \mathrm{~F}$ Alconox solution wash, cold-running-water rinse, $180 \mathrm{~F}$ water rinse, cold-running-water rinse, and a $200 \mathrm{~F}$ water rinse followed by drying with forced filtered air.

The solid zirconium hydride was cleaned after machining in a solution consisting of 10 parts hydrofluoric acid and 90 parts water. The core was then rinsed in cold running water and subjected to the same series of wash-and-rinse cycles as the stainles stecl.

The powdered zirconium hydride was polished with $600 \mathrm{~A}-$ grit silicon carbide paper and wiped dry with clean paper towels.

The molybdenum barrier layers were taken from clean as-rolled sheet stock, degreased with acetone, pickled in a solution consisting of 10 parts hydrofluoric acid and 90 parts water, rinsed in cold running water, and subjected to the same series of wash-and-rinse cycles as used for the stainless steel.

The niobium barrier layers were taken from clean as-rolled sheet and subjected to the same cleaning cycle as the stainless steel.

The copper barrier-layer material was prepared from as-rolled phosphorusdeoxidized copper sheet. The copper was pickled in a solution of 10 parts of sulfuric acid and 90 parts water, rinsed in cold water, and subjected to the same wash cycle as the niobium and stainless steel.

During the cleaning process, all components were handled with clean rubber gloves during washing and with clean white cloth gloves during the drying and assembling operations. This was done to prevent recontamination of the cleaned surfaces. After cleaning, the components were immediately assembled.

\section{Assembly and Evacuation of Compacts for Pressure Bonding}

Immediately after cleaning, the components were carefully assembled into tubes or cans, depending upon the type of specimen. The canned assemblies were directly placed into a controlled-atmosphere weld tank for welding of the end plugs. Two welding passes using stainless steel filler rod were made on the end plugs of both the tubes and cans.

CONFIDENTIAL 
The welded compacts were unloaded from the welding tank and tested for leaks. A high-pressure hose was clamped to the evacuation tube of each compact and 50 to $75 \mathrm{psi}$ of helium pressure was applned to the inside of each compact. The compacts were then immersed into hot water and observed for possible leaks. This method was found to be more reliable than the use of a mass spectrograph with helium at atmospheric pressure.

If no leaks were observed, the compacts were immediately evacuated for at least $24 \mathrm{hr}$ to a pressure of $5 \times 10^{-3} \mathrm{~mm}$ of mercury or less. The evacuated compacts were then sealed and placed into the furnace inside the high-pressure autoclave for pressure bonding.

\section{CLADDING AND BOND EVALUATION}

\section{Evaluation Procedures for Clad Specimens}

A portion of the specimens clad in this study were evaluated immediately after pressure bonding. The remainder wexe thermal cycled between 700 and $1500 \mathrm{~F}$ at various temperature and time differentials before being evaluated. The clad specimens were evaluated on the basis of metallographic examination, mechanical peel tests, and hydrogen-retention studies.

The metallographic inspections for bond uniformity and continuity were made on buth the transverse and longitudinal sections of the clad specimens.

A mechanical peel test to evaluate the bonds between components was conducted as outlined below:

(1) The rod specimens were cut in half transversely. The evacuation-tube end was then cut in half longitudinally and one of the se quarters was used in the peel test. The flat-plate specimens were cut in half transversely and a 1/4-in. section cut from the evacuation-tube end. The cladding on one side of the 1/4-in. section was then cut through to allow for peeling.

(2) The test sections were placed and held one at a time in a vise. Pliers were used in an attempt to peel one component from another.

(3) The assumed degree of bond was determined by how the cladding or barrier layers peeled from the core or from one another. The four degrees of bonding are listed below:

(a) No bonding if one component parted or fell apart from another with little or no pressure being applied with the pliers.

(b) Fair bonding if there was a tearing of one component from the other, but this separation took place ahead of the pliers.

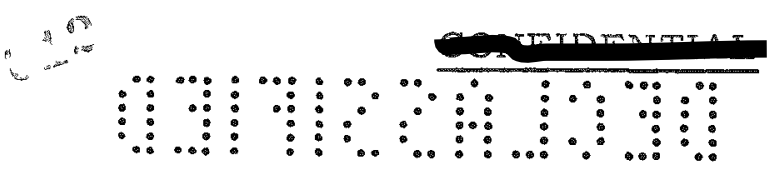


(c) Good bonding if there was a tearing where the pliers were being applied and particles were torn from one or the other components.

(d) Excellent bonding if the two components could not be separated or there was a tearing away of large chunks from one or the other components.

The hydrogen content of the zirconium hydride specimen after pressure bonding was determined by vacuum-fusion analysis.

Preliminary Bonding Studies

In the initial portion of the cladding study, cursory scxeening tests were conducted for the purpose of guiding the development phase of the program. Three series of specimens were bonded utilizing varying conditions of time and pressure to achieve bonding. In each series of specimens, barrier layers consisting of molybdenum, niobium, and composite layers of molybdenum and niobium with copper were investim gated. Included also for comparison was a low-hydride specimen of approximately $\mathrm{ZrH}_{0} .85$ and a zirconium specimen.

Each series of specimens consisted of 14 rod specimens 0.250 in. in diameter by $0.750 \mathrm{in}$. in length. The specimens were closely fit into Type 304 stainless steel tubes as shown in Figure 1. The initial set was bonded for $4-1 / 2 \mathrm{hr}$ at $1700 \mathrm{~F}$ with a helium gas pressure of 10,000 psi. Examination of these specimens indicated that it was desirable to pressure bond at higher temperatures in order to improve the strength of the stainless-to-stainless bond. The next set was bonded in a two-step operation: $4 \mathrm{hr}$ at $1650 \mathrm{~F}$ followed by $2 \mathrm{hr}$ at $1800 \mathrm{~F}$ with a pressure of $10,000 \mathrm{psi}$. The third set was also bonded with a two-step treatment: $2 \mathrm{hr}$ at $1800 \mathrm{~F}$ followed by $2-1 / 2 \mathrm{hr}$ at $1900 \mathrm{~F}$ at $10,000 \mathrm{psi}$. The two-step treatment was used in an effort to prevent excessive dissociation of the hydride. In these sets of specimens, intimate contact and a partial bond was established between the components at the lower temperature. The specimens were then cooled to room temperature and treated at the higher temperature to improve the stainless-to-stainless bond strength.

The pressure-bonded specimens were evaluated by use of metallography, peel tests, and hydrogen-retention studies. This evaluation was made on the specimens both before and after thermal cycling. Screening of the specimens after pressure bonding was accomplished by a combined evaluation using metallography and bondstrength tests to determine the degree and quality of bonding.

No noticeable dimensional changes were observed in the diameter of the specimens pressure bonded at $1700 \mathrm{~F}$ for $4-1 / 2 \mathrm{hr}$. The peel test showed that a fair bond was achieved between stainless to stainless, but the bond was weak in comparison to a roll-clad bond obtained above $1850 \mathrm{~F}$. This bond was improved in the specimens pressure bonded in the two-step treatment at 1650 and $1800 \mathrm{~F}$. The bond was comparable to that obtained in roll bonding in the series of specimens bonded in a two-step 
operation at 1800 and $1900 \mathrm{~F}$. This is illustrated in a transverse section of a specimen in Figure 6 which is typical of the stainless-to-stainless bonds achieved in this set of specimens.

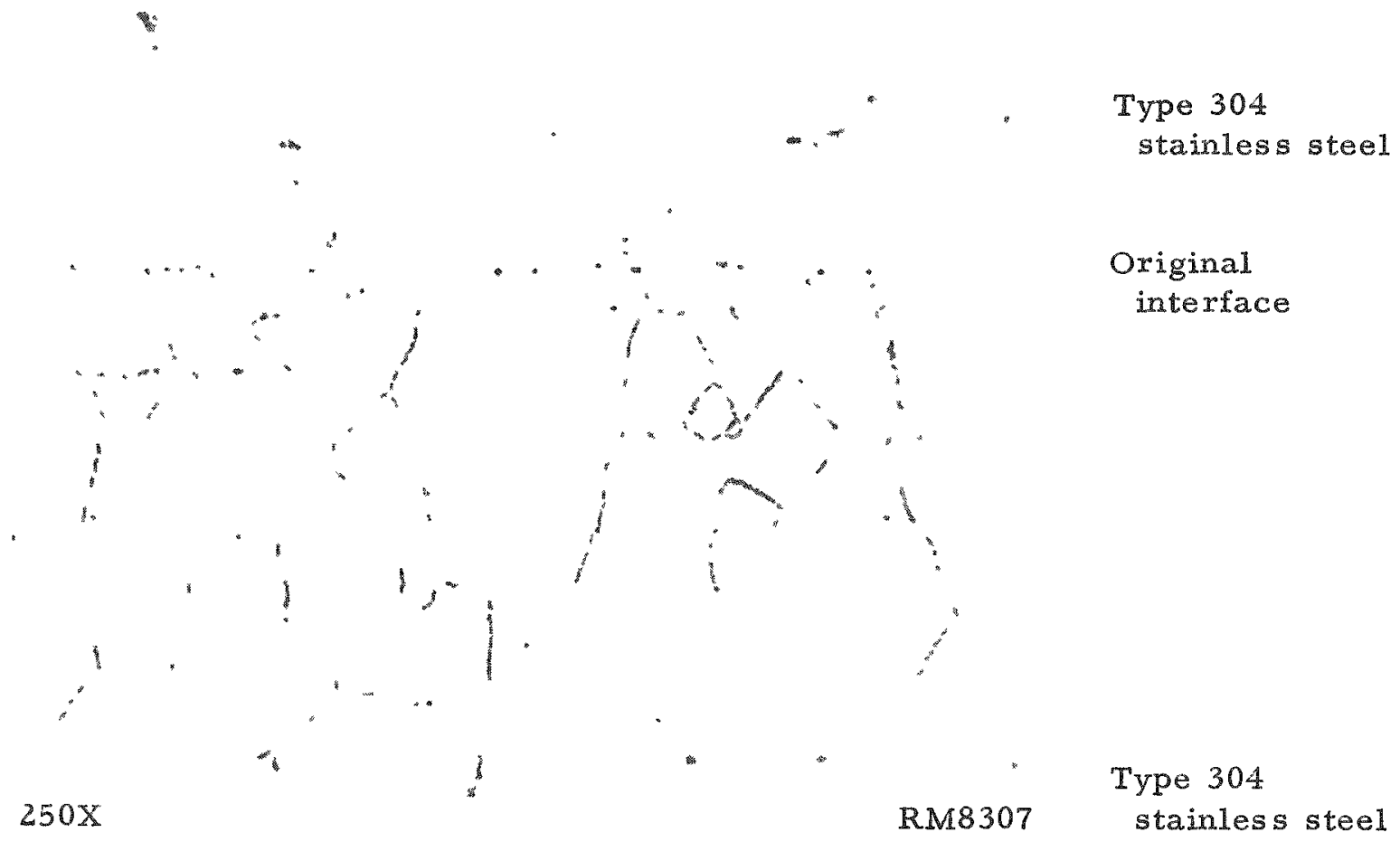

\section{FIGURE 6. TYPICAL TRANSVERSE SECTION OF THE STAINLESS-TO-STAINLESS BOND}

Specimen 1900-8, pressure bonded at 10,000 psi for $2 \mathrm{hr}$ at $1800 \mathrm{~F}$, allowed to cool to room temperature, and run for $2-1 / 2 \mathrm{hr}$ at $1900 \mathrm{~F}$.

The results of bonding and evaluation of the preliminary test specimens are discussed below.

General Evaluation of Specimens Pressure Bonded $4-1 / 2 \mathrm{Hr}$ at $1700 \mathrm{~F}$ at $10,000 \mathrm{psi}$

Examination of the stainless-to-stainless bonds revealed an intimate contact between the two and a visible bond line. The peel test showed that a fair bond was achieved, but the bond was not as strong as that obtained by roll cladding at 1850 to $2200 \mathrm{~F}$.

It was noted that where the copper barrier layer came in contact with the zirconium hydride, a bond was achieved which had a large diffusion zone. After thermal cycling, the diffusion-zone growth was observed to be extensive. $\therefore:$

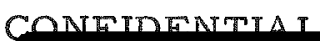

, 
All components were measured with a micrometer, and the readings recorded before pressure bonding. After being clad, the measurements were checked with both a micrometer and an optical comparator and the readings recorded. No noticeable dimensional changes were observed in the diameter of the core, or the thickness of the cladding or barrıer-layer materials, except where the barrier-layer sheet materials beveled out at the edges or defective cores were used.

General Evaluation of Specimens Pressure Bonded at 10,000 psi at 1650 for $4 \mathrm{Hr}$ and Rerun for $2 \mathrm{Hr}$ at $1800 \mathrm{~F}$

Examination of the stainless-to-stainless bond revealed a slight amount of growth across the original interface, which was still visible. This bond appeared better when peel tested than the bond obtained at $1700 \mathrm{~F}$ for $4 \mathrm{hr}$, but weaker than a bond between stainless and stainless achieved by roll cladding at 1850 to $2200 \mathrm{~F}$.

No noticeable dimensional changes were observed in the series of specimens during bonding in the diameter of the core, or the thickness of the cladding or barrierlayer materials, except where the barrier-layer sheet materials beveled out at the edges or if defective cores were used.

General Evaluation of Specimens Pressure Bonded $2 \mathrm{Hr}$ at $1800 \mathrm{~F}$ and Rerun $2-1 / 2 \mathrm{Hr}$ at $1900 \mathrm{~F}$ at 10,000 psi

Examination of the stainless-to-stainless bonds revealed them to be good when peel tested and grain growth across the original interface was observed at all points examined. This is illustrated in a transverse section of a specimen in Figure 6, which is typical of the stainless-to-stainless bonds achieved in the third set.

As in the first and second sets, all components were measured caxefully before and after bonding. Again, no noticeable changes were observed in the diameter of the core, or the thickness of the cladding or barrier-type materials, except where the barrier-layer sheet materials beveled out at the edges or defective cores were used.

Evaluation of Copper-Molybdenum Barrier-Layer Specimens

Specimens consisting of a copper barrier layer adjacent to the stainless and a molybdenum barrier layer next to the hydride core were pressure bonded $4-1 / 2 \mathrm{hr}$ at $1700 \mathrm{~F}$. No apparent metallurgical bond was achieved between the zirconium hydride and the molybdenum, and the molybdenum did not conform to the surface of the core during pressure bonding. The peel test revealed a good copper-molybdenum bond and a good-to-excellent copper-stainless bond. 
The two-step bonding process of $4 \mathrm{hr}$ at $1650 \mathrm{~F}$ and $2 \mathrm{hr}$ at $1800 \mathrm{~F}$ failed to greatly improve the molybdenum-to-hydride bond; however, some improvement was noted in bond strength for the copper-molybdenum and copper-stainless bonds. Specimens pressure bonded $2 \mathrm{hr}$ at $1800 \mathrm{~F}$ and $2-1 / 2 \mathrm{hr}$ at $1900 \mathrm{~F}$ exhibited a partial bond between the molybdenum and the zirconium hydride. Peel tests revealed this bond to be fair. The molybdenum made intimate contact with the zirconium hydride core, filling voids and machine marks. The peel test also revealed a good copper-stainless bond, bul a weak, brittle copper-molybdenum interface. Figure 7 shows a typical transverse section of a specimen in the as-bonded condition. The best bonding for this system was obtained with this two-step high-temperature treatment.

Type 304

stainless steel

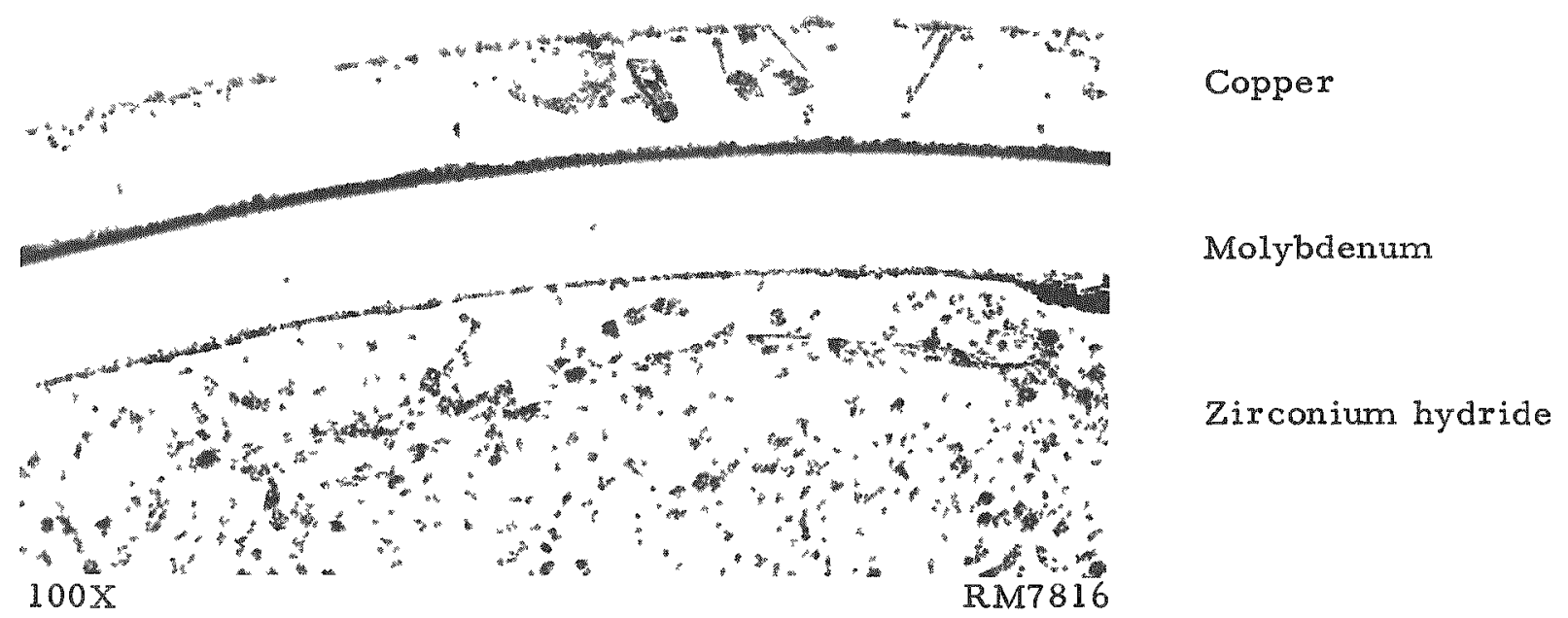

EIGURE 7. TYPICAL TRANSVERSE SECTION OE A COPPER-MOLYBDENUM BARRIER-LAYER SPECIMEN

Specimen 1900-2, pressure bonded at 10,000 psi for $2 \mathrm{hr}$ at $1800 \mathrm{~F}$, allowed to cool to room temperature, and rerun for $2-1 / 2 \mathrm{hr}$ at $1900 \mathrm{~F}$.

Evaluation of Copper-Niobium Barrier-Layer

Specimens

Composite barrier-layer specimens, containing a double barrier of copper and niobium with the copper adjacent to the cladding were pressure bonded at $1700 \mathrm{~F}$ for 4-1/2 hr and produced a partial bond between the zirconium hydride and the niobium. The niobium filled voids and machine marks on the zirconium hydride core; however,

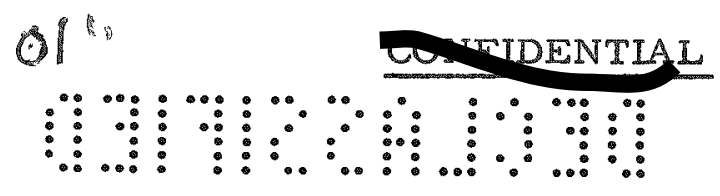


the bond appeared to be only fair when peel tested. The bonds achieved between copper and niobium and copper and stainless were good to excellent in the peel test.

Specimens with the copper-niobium barriex-layer system pressure bonded at $1650 \mathrm{~F}$ for $4 \mathrm{hr}$ and $2 \mathrm{hr}$ at $1800 \mathrm{~F}$ exhibited an improvement in the core-to-niobium bond; however, peel tests of these specimens indicated that they were only partially bonded. The other bonds in the system were all good as evidenced by peel tests and metallographic examination.

Pressure bonding by the two-step high-temperature treatment produced a significant improvement in the bonding between the core and niobium layer. The improvement is best illustrated by a comparison of this system pressure bonded at $1700 \mathrm{~F}$ for $4-1 / 2 \mathrm{hr}$ in Figure 8 and a similar specimen pressure bonded at $1800 \mathrm{~F}$ for $2 \mathrm{hr}$ and rerun at $1900 \mathrm{~F}$ for $2-1 / 2 \mathrm{hr}$ in Figure 9. Even with the obvious improvement in bonding observed in Figure 9, the problem of copper coming into contact with the core through a pinhole or crack in the niobium still persists in this system. If a barrier-layer defect exists, the interface fails rapidly as a result of diffusion between the copper and core.

Evaluation of Molybdenum-Barrier-Layer Specimens

The evaluation of the molybdenum-barrier specimen pressure bonded for $4-1 / 2$ hr at $1700 \mathrm{~F}$ indicated that no bonding was achieved between the zirconium hydride and the molybdenum barrier layer. In addition, the molybdenum did not conform to the zirconium hydride core. A slight diffusion zone was visible along the bond between the stainless steel and the molybdenum which proved to be only fair when peel tested.

Increased bonding temperatures and the two-step method of bonding improved all of the bonds in this system. Again the best results were obtained with the two-step high-temperature bonding operation. The high-temperature treatment is necessary to properly deform the molybdenum barriex to produce intimate contact between the molybdenum and the core which is necessary to obtain good bonding action.

Figure 10 represents a specimen pressure bonded at $1650 \mathrm{~F}$ for $4 \mathrm{hr}$ and rerun $2 \mathrm{hr}$ at $1800 \mathrm{~F}$, both at $10,000 \mathrm{psi}$. The only difference between this specimen and a similar specimen bonded at the higher temperatures is that there is less good contact between the core and the barrier layer. This lack of contact can be observed along the core-to-barrier layer interface in this figure. In general, the molybdenum-to-core bond was fair using the high-temperature treatment.

Evaluation of Niobium-Barrier-Layer Specimens

Examination of the niobium-barrier-layer specimens revealed that a partial bond was achieved in $4-1 / 2 \mathrm{hr}$ at $1700 \mathrm{~F}$ at 10,000 psi between the zirconium hydride and the niobium, which conformed to the core. When peel tested, the zirconium hydrideniobium bond appeared fair and the niobium-stainless bond appeared fair to good.

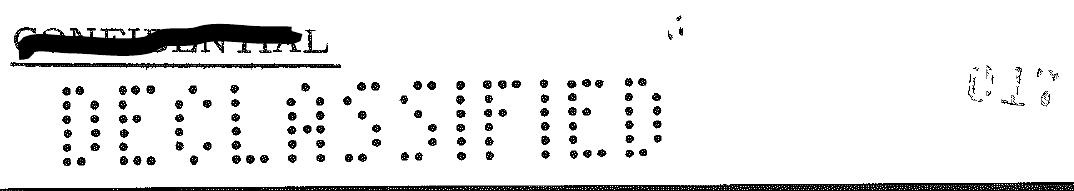




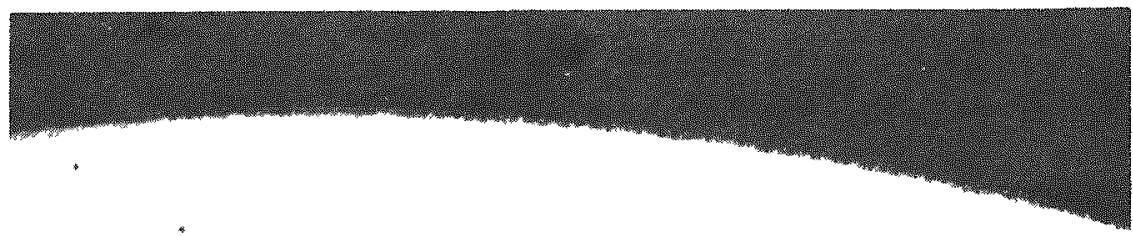

Type 304

stainless steel

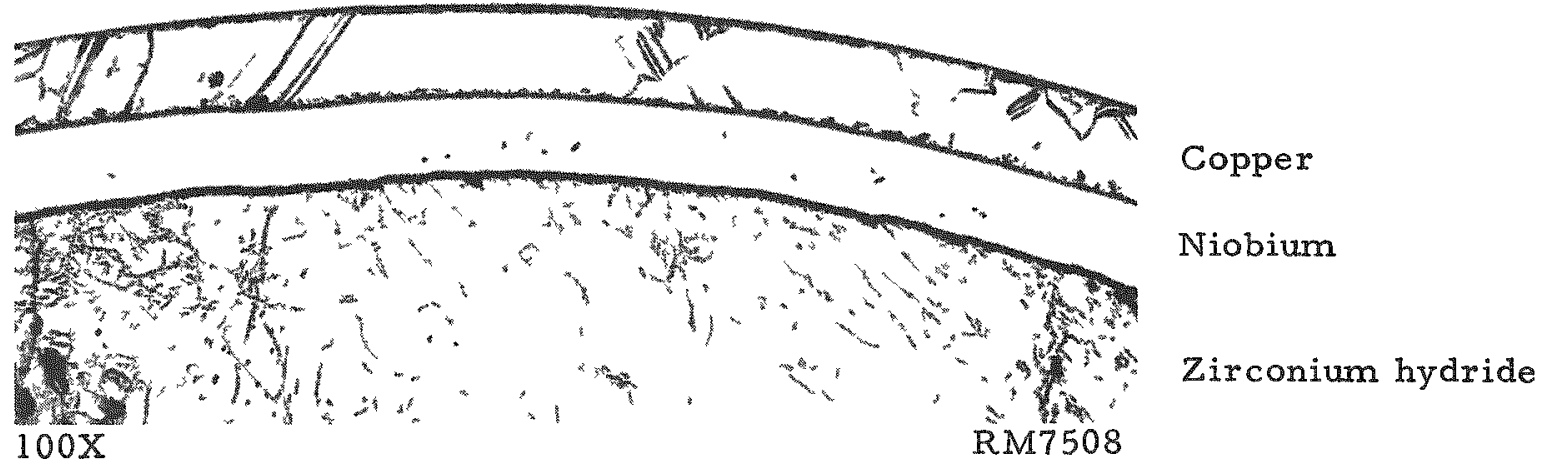

FIGURE 8. SPECIMEN WITH A COPPER-NIOBIUM BARRIER LAYER

Specimen 1700-3, pressure bonded at 10,000 psi for $4-1 / 2$ hr at $1700 \mathrm{~F}$.

Type 304

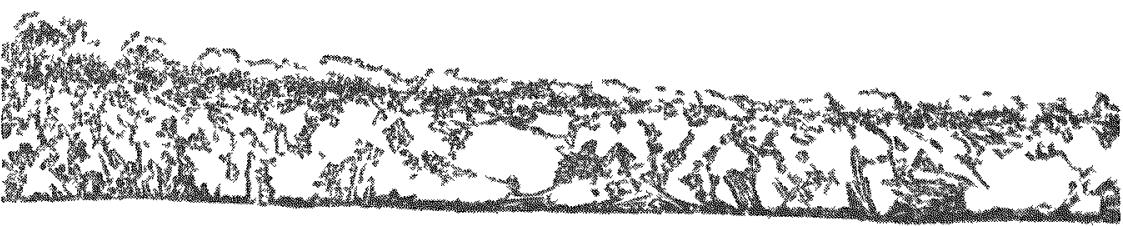
stainless steel

Copper

Niobium

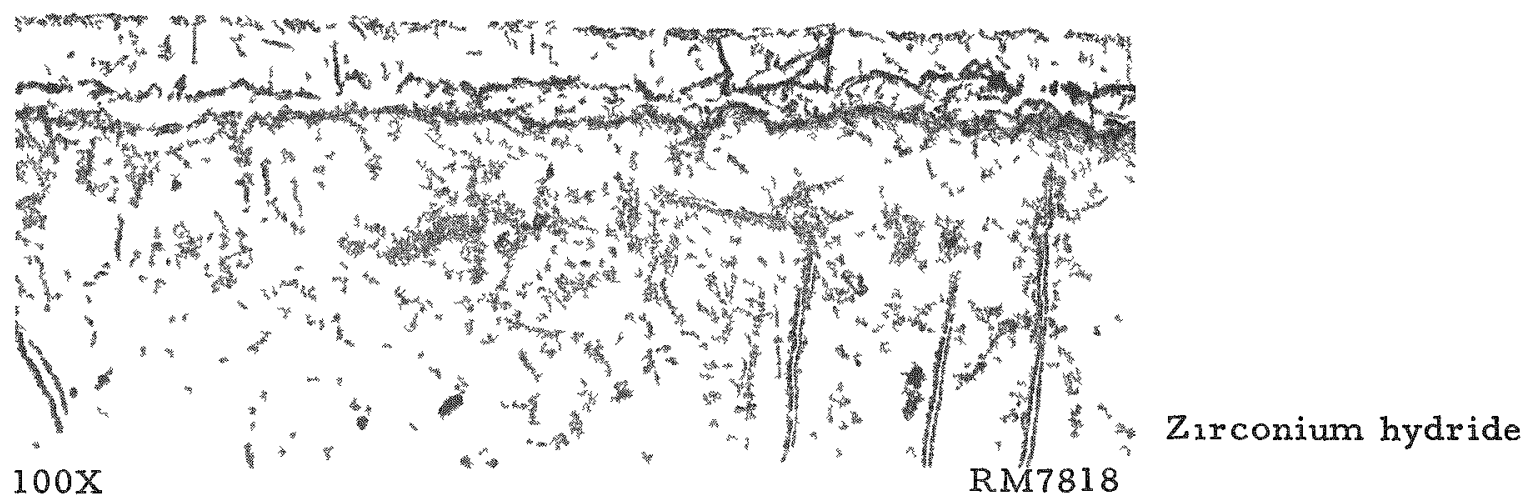

FIGURE 9. SPECIMEN WITH A COPPER-NIOBIUM BARRIER LAYER

Specimen 1900-3, pressure bonded at 10,000 psi for $2 \mathrm{hr}$ at $1800 \mathrm{~F}$, allowed to cool to room temperature, and rerun for $2-1 / 2 \mathrm{hr}$ at $1900 \mathrm{~F}$.

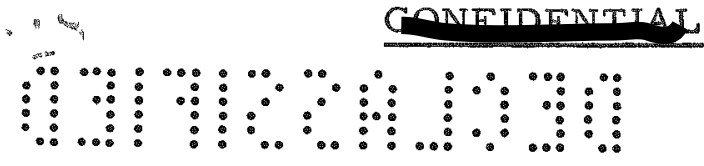


Type 304 stainless steel

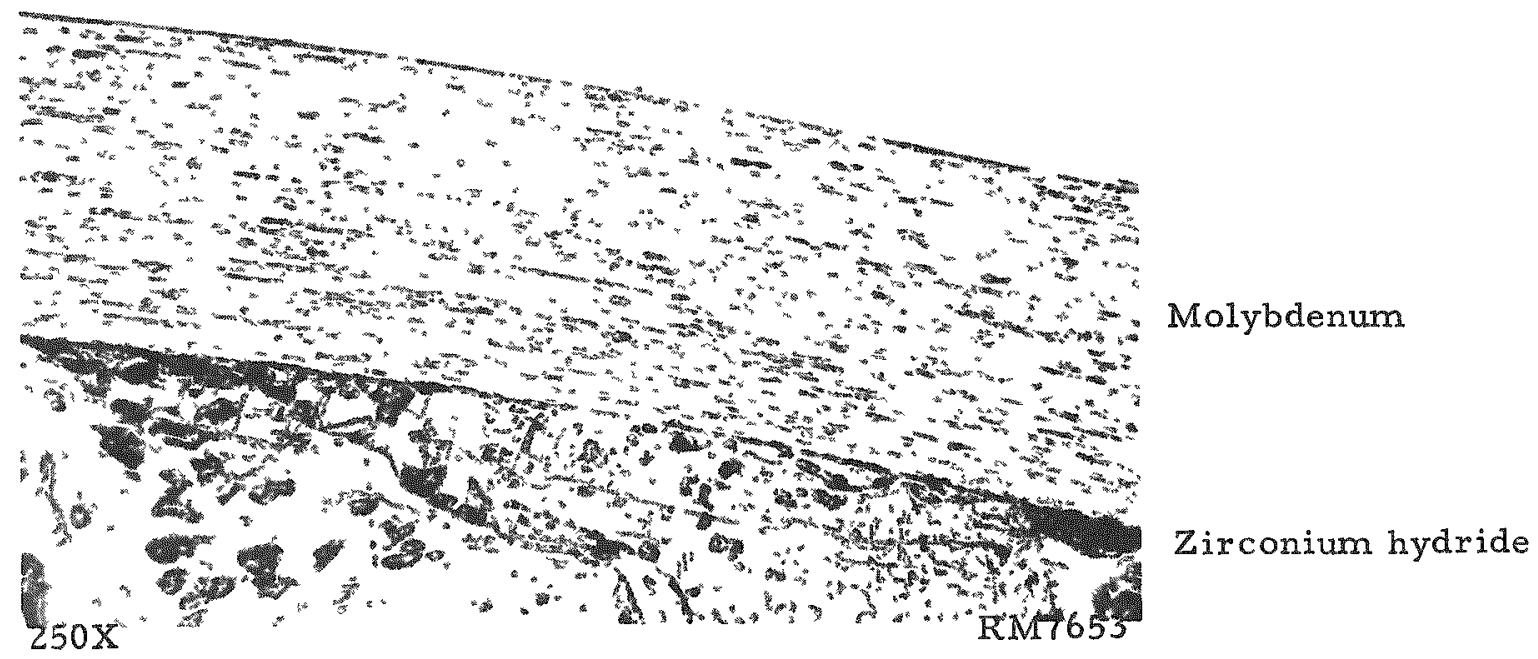

FIGURE 10. SPECIMEN WITH A MOLYBDENUM BARRIER LAYER

Specimen 1800-5, pressure bonded at 10,000 psi for $4 \mathrm{hr}$ at $1650 \mathrm{~F}$, allowed to cool to room temperature, and rerun for $2 \mathrm{hr}$ at $1800 \mathrm{~F}$ at $10,000 \mathrm{psi}$. 
The specimen prepared by bonding at $1650 \mathrm{~F}$ for $4 \mathrm{hr}$ and rerun at $1800 \mathrm{~F}$ for $2 \mathrm{hr}$ produced significant improvement in the strength of the niobium-to-stainless bond and the core-to-niobium bond. No significant improvement was obtained with the twostep high-temperature $(1800$ and $1900 \mathrm{~F})$ pressure-bonding treatment. Figure 11 , which shows a specimen pressure bonded at 1650 and rerun at $1800 \mathrm{~F}$, illustrates the best bonding action obtained for this system.

Evaluation of Type 304 Stainless Steel-Clad

Specimens

Direct cladding of zirconium hydride with stainless steel appeared to produce good bonds for all three pressure-bonding procedures, as evidenced by peel tests. The stainless steel was in intimate contact with the core at all points examined and a good bond was obtained between core and cladding. Figure 12 shows a typical area of a specimen prepared by direct cladding of zirconium hydride with stainless steel. Based on metallographic and bond-strength examinations of as-bonded specimens, the direct cladding of zirconium hydride with stainless steel produced the best results. It must be kept in mind that these results are for delta-phase hydride and do not necessarily apply for other hydrides, as will be discussed later.

Evaluation of Type 304 Stainless Steel-Clad Defective-Core Specimens

Cracked zirconium hydride cores were purposely used in this series of specimens to explore the possibility of cladding and utilizing such cores with the pressure-bonding conditions used to bond this series.

Examination of the as-bonded specimen showed a stainless steel-to-zirconium hydride bond comparable with that of a sound specimen. A typical section of the specimen is shown in Figures 13 and 14. The stainless steel filled voids 0.005 to 0.015 in. deep; however, microscopic examination revealed a slight crushing of the edges of these voids. The stainless steel ruptured during filling of voids in excess of $0.015 \mathrm{in}$. deep during pressure bonding. Except for thinning of the cladding and crushing of the core along the defect, these specimens yielded the same results during pressure bonding as were obtained with direct cladding of sound specimens.

Evaluation of Type 304 Stainless Steel-Clad

$\mathrm{Zx \textrm {H } _ { 0 } . 8 5 \text { Specimen }}$

A low-hydride core, approximately $\mathrm{Zr} \mathrm{H}_{0} .86$, was pressure bonded for a comparison study with the delta-phase hydride. A transverse section of the specimen is shown in Figure 15. The specimen appeared to have bonded, with a slight amount of diffusion visible, only to rupture during cooling. The peel test revealed weak areas and brittle bonds. Bonding for $4-1 / 2 \mathrm{hr}$ at $1700 \mathrm{~F}$ produced the best bond for the three pressure-bonding parameters investigated. Higher bonding temperatures appeared to increase the amount of the brittle interface material. Comparisons between the direct cladding of delta-phase and alpha-phase hydride shows that a brittle interface is formed when using alpha-phase material.

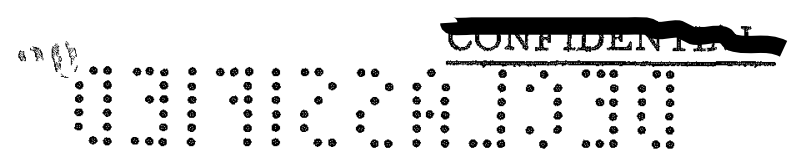


Type 304 stainless steel

Niobrum

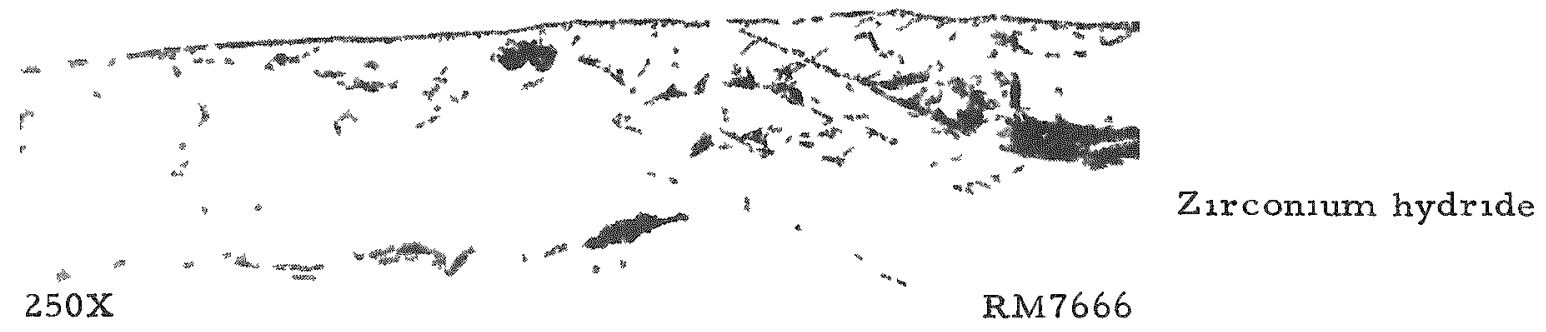

FIGURE 11. SPECIMEN WITH A NIOBIUM BARRIER LAYER

Specimen 1800-7, pressure bonded at 10,000 psi for $4 \mathrm{hr}$ at $1650 \mathrm{~F}$, allowed to cool to room temperature, and rerun for $2 \mathrm{hr}$ at $1800 \mathrm{~F}$ at $10,000 \mathrm{psi}$

Type 304 stanless steel

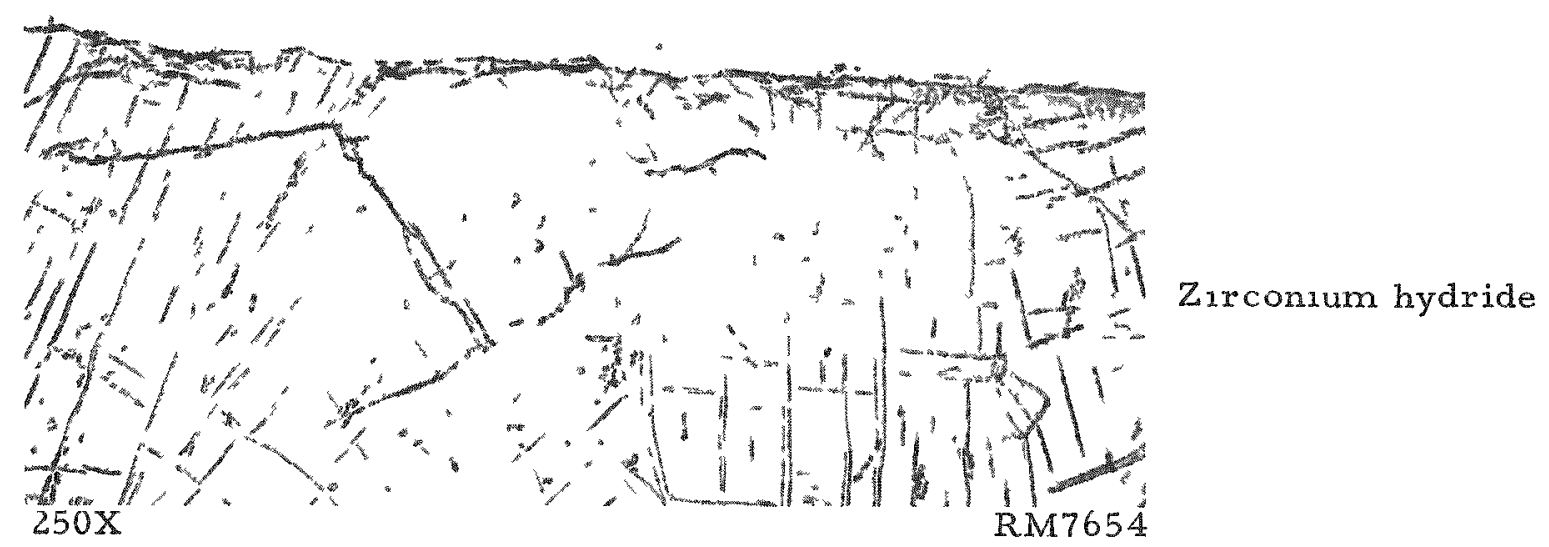

FIGURE 12. TYPE 304 STAINLESS STEEL-CLAD SPECIMEN

Specimen 1800-9, pressure bonded at 10,000 psi for $4 \mathrm{hr}$ at $1650 \mathrm{~F}$, allowed to cool to room temperature, and rerun for $2 \mathrm{hr}$ at $1800 \mathrm{~F}$ at 10,000 psi.






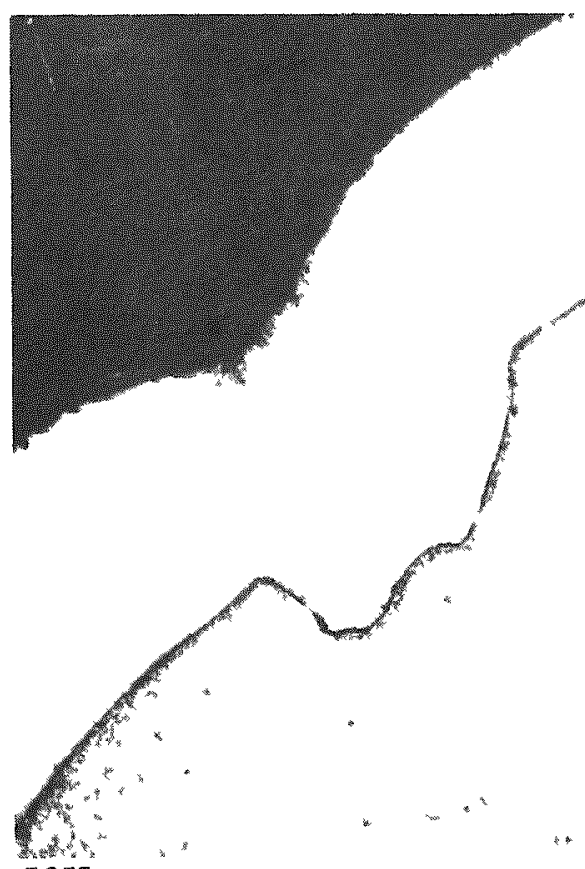

$50 \mathrm{x}$

Type 304 stainless steel

Zirconium hydride

FIGURE 13. TYPE 304 STAINLESS STEEL-CLAD DEFECTIVE-CORE SPECIMEN Specimen 1900-12, pressure bonded at 10,000 psi for $2 \mathrm{hr}$ at $1800 \mathrm{~F}$, allowed to cool to room temperature, rerun for $2-1 / 2 \mathrm{hr}$ at $1900 \mathrm{~F}$, and thermal cycled 126 times between 750 and $1500 \mathrm{~F}$ at various temperature differentials. This photomicrograph is a transverse section showing the deformation of the stainless cladding into a crack in the zirconium hydride core.

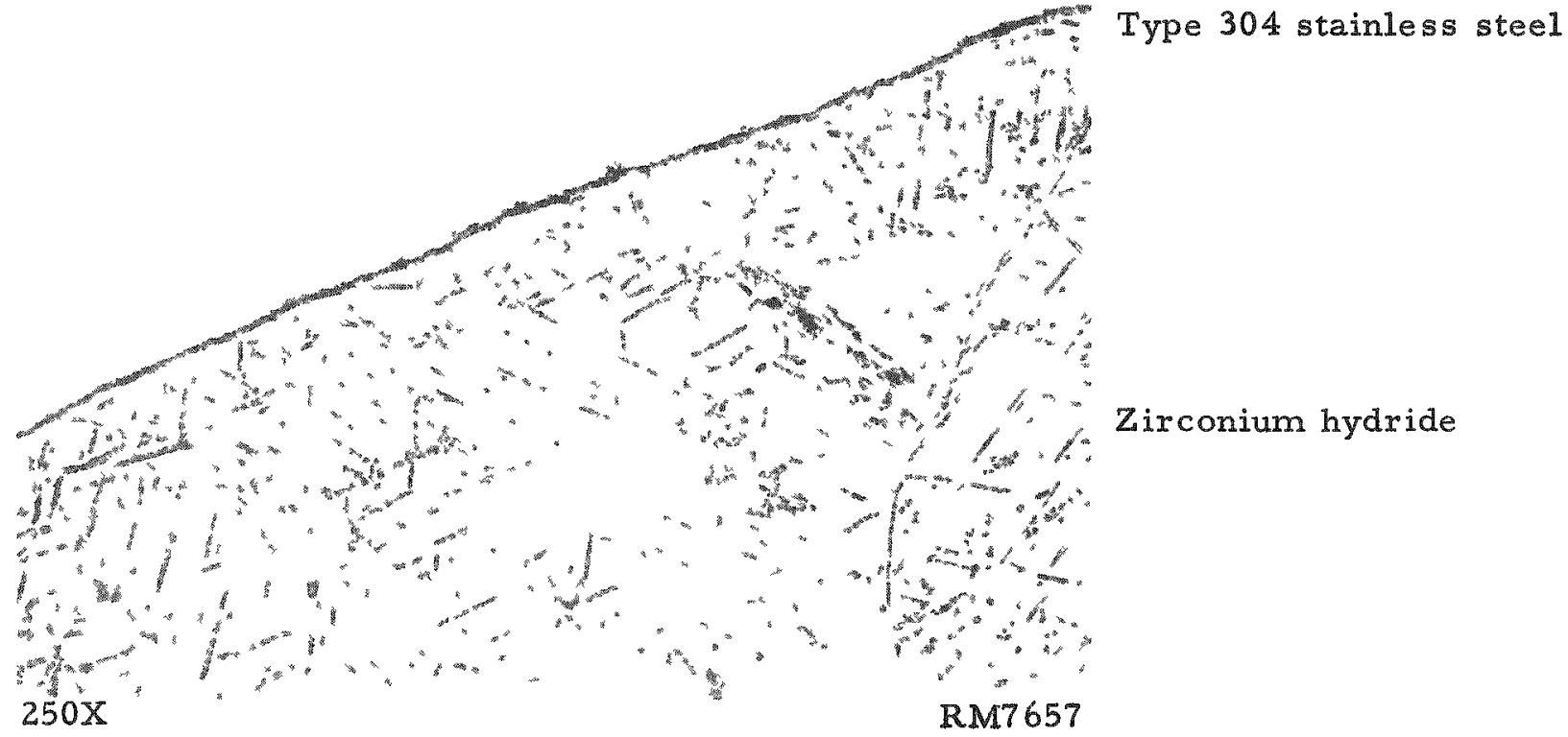

FIGURE 14. TYPE 304 STAINLESS STEEL-CLAD DEFECTIVE-CORE SPECIMEN

Specimen 1800-11, pressure bonded at 10,000 psi for $4 \mathrm{hr}$ at $1650 \mathrm{~F}$, allowed to cool to room temperature, and rerun for $2 \mathrm{hr}$ at $1800 \mathrm{~F}$ at

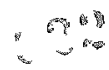
10,000 psi. 

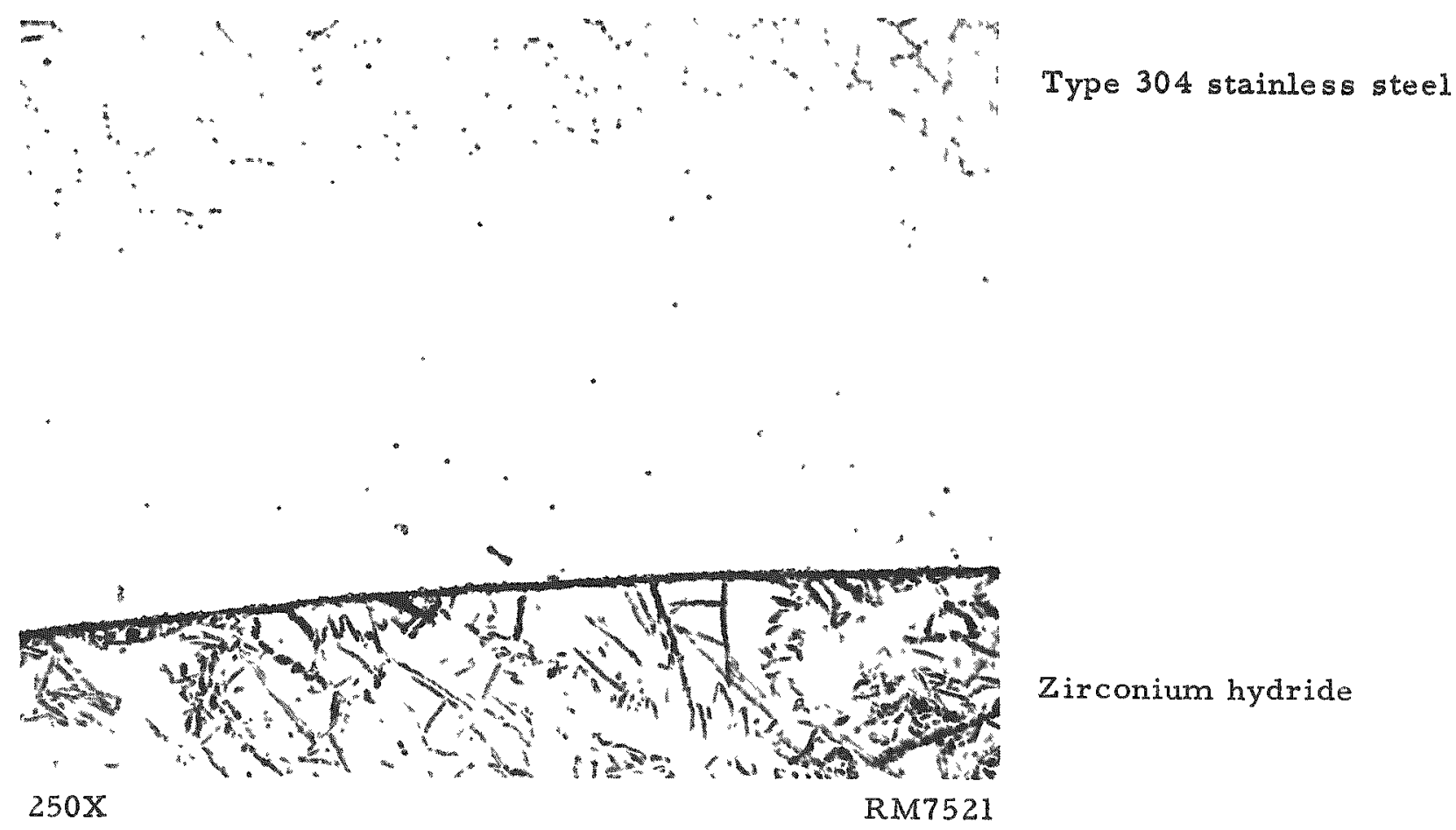

FIGURE 15. TYPE 304 STAINLESS STEEL-CLAD Z $\mathrm{rH}_{0 .} 86$ SPECIMEN Specimen 1700-13, pressure bonded at 10,000 psi for 4-1/2 hr at $1700 \mathrm{~F}$. 
Evaluation of Type 304 Stainless Steel-Clad

Zirconium Specimen

In addition to the low-hydride core, a zirconium core was used for a further comparison study of bonding of the hydrides as compared to cladding of zirconium with stainless steel. From the first observation, it was apparent that the delta-phase zirconium hydride did not appear to alloy with the stainless steel in the same manner as zirconium. In addition, diffusion between the zirconium and the stainless steel was extensive and the bond ruptured and separated while cooling from the pressure-bonding temperature. In the low-hydride core, diffusion and alloying were similar to the zirconium but occurred to a lesser degree. A section of a stainless steel-clad zirconium specimen is shown in Figure 16.

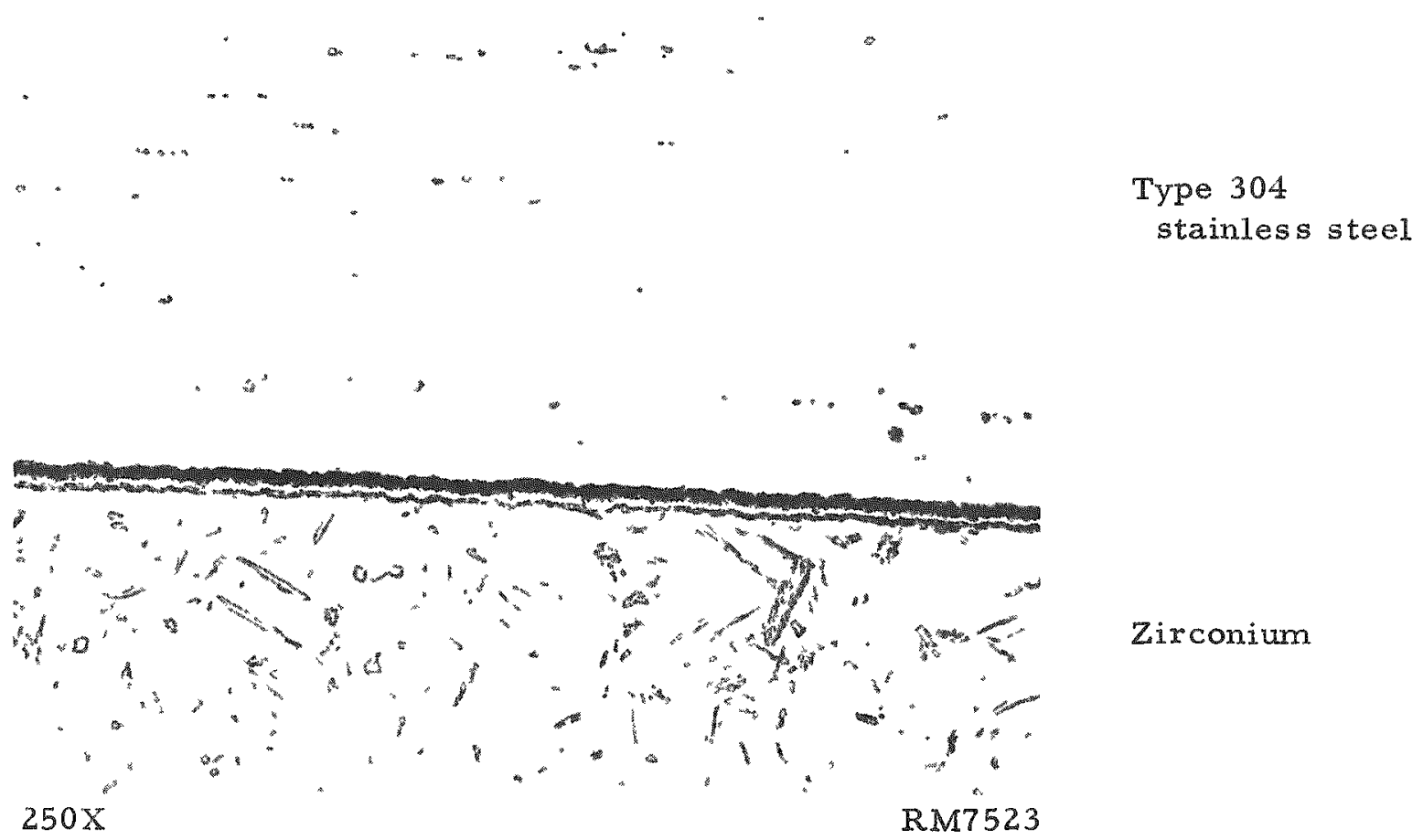

FIGURE 16. TYPE 304 STAINLESS STEEL-CLAD ZIRCONIUM SPECIMEN

Specimen $1700-14$, pressure bonded at 10,000 psi for $4-1 / 2 \mathrm{hr}$ at $1700 \mathrm{E}$.

Thermal-Cycling Tests

After the examination of the as-bonded specimens was completed, thermalcycling tests were $r$ un in an attempt to further screen the bonded systems. It became apparent after each thermal-cycling test that a more severe thermal-cycling test would be necessary to accomplish any significant screening of specimens. The specimens were cycled over a temperature range from 1000 to $1500 \mathrm{~F}$ with an average $\Delta \mathrm{T}$ of $300 \mathrm{~F}$.

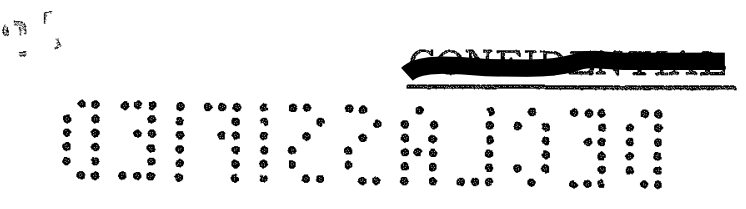


Specimens containing molybdenum-copper barrier layers exhibited no appreciable effects from the thermal-cycling tests except for axeas in the interface where the copper came into contact with the zirconium hydride. In these areas the diffusion was more extensive than in the as -bonded condition.

The niobium-copper interface responded to thermal cycling in the same manner as the molybdenum-copper interface. The best results based on thermal cycling were obtained on the specimen pressure bonded at $1700 \mathrm{~F}$ for $4-1 / 2 \mathrm{hr}$ at $10,000 \mathrm{psi}$.

No evidence of bond rupture or extencive diffusion was observed for the molybdenum- and niobium-barrier-layer specimens after thermal cycling.

No apparent difference, except for a slight increase in the amount of diffusion, was observed on the specmens prepared by direct cladding of zirconium hydride with stainless steel. The specimen shown in Figure 17 was pressure bonded at $1700 \mathrm{~F}$ for $4-1 / 2 \mathrm{hr}$ at $10,000 \mathrm{psi}$ and thermal cycled 70 times and does not show any significant increase in diffusion in comparison with the as-bonded specimen in Figure 12. This does not apply, however, for the specimen shown in Figure 18 of a specimen pressure bonded at $1650 \mathrm{~F}$ for $4 \mathrm{hr}$ and at $1800 \mathrm{~F}$ for $2 \mathrm{hr}$ at $10,000 \mathrm{psi}$ and thermal cycled 98 times. The difference in diffusion may be either a function of bonding temperatures, amount of the rmal cycling, or hydrogen dissociation.

Sufficient time was available in thrs investigation to permit a full evaluation of the effects of thermal cycling on the bond interfaces prepared. The intent was to use this as a screening tool. Based on the investigation conducted, the direct cladding of zirconium hydride was the only system that appeared to be affected by the thermalcycling tests. None of the zirconium hydride cores, except those which were defective, cracked during pressure bonding or thermal cycling.

\section{Hydrogen-Retention Studies}

Analyses for hydrogen were obtained for the as-bonded specimens and for those as bonded and thermal cycled. The results for the pressure-bonded specimens are contained in Tables 1, 2, and 3. No significant loss of hydrogen was detected during thermal cycling. It should also be pointed out that no correlation is possible for the retention of hydrogen between the various barrier materials, as only the wall of the specimens was clad with the barrier.

It is evident from the hydrogen analyses that an appreciable loss of hydrogen. occurs during the high-temperature pressure-bonding operations. Apparently only the $1700 \mathrm{~F}$ temperature and $4-1 / 2-\mathrm{hr}$ time may be suitable for pressure bonding. There are, however, several techniques that can be used to obtain excellent bonding without excessive loss of hydrogen. Perhaps the most desirable is to bond with a heliumhydrogen gas mixture. By use of a partial pressure of hydrogen it is possible to balance the dissociation pressure of the hydrogen. It should also be possible to start bonding with a higher than desired hydrogen content and by careful control of the process obtain the desired hydrogen content. Another technique is to use the two-step 
Type 304 stainless steel

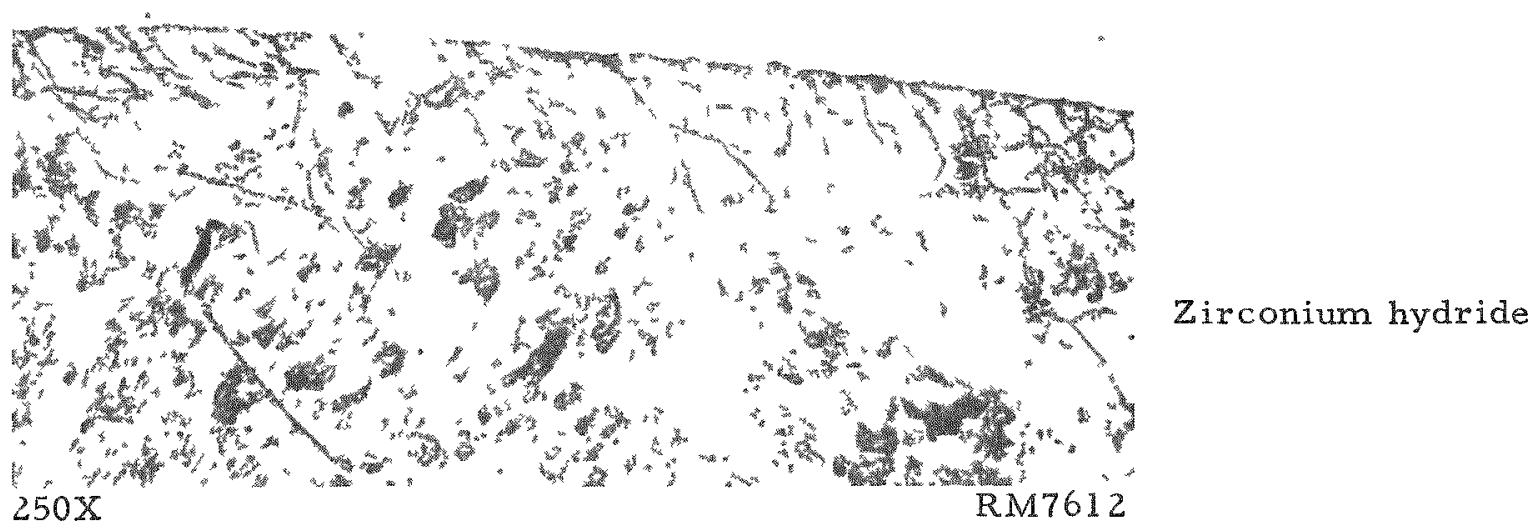

FIGURE 17. THERMAL-CYCLED TYPE 304 STAINLESS STEEL-CLAD SPECIMEN

Specimen 1700-10, pressure bonded at 10,000 psi for 4-1/2 hr at $1700 \mathrm{~F}$ and thermal cycled 70 times between 770 and $1500 \mathrm{~F}$ at various temperature differentials.

Type 304 stainless steel

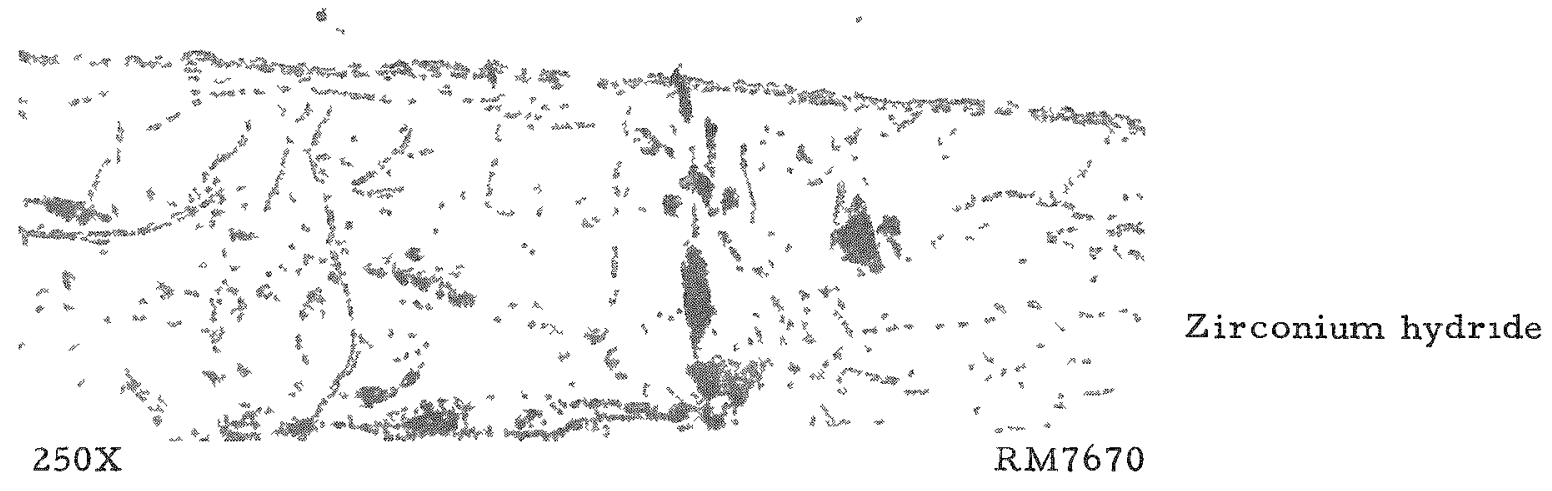

FIGURE 18. THERMAL-CYCLED TYPE 304 STAINLESS STEEL-CLAD DEFECTIVECORE SPECIMEN

Specimen 1800-12, pressure bonded at 10,000 psi for $4 \mathrm{hr}$ at $1650 \mathrm{~F}$, allowed to cool to room temperature, rerun for $2 \mathrm{hr}$ at $1800 \mathrm{~F}$ at $10,000 \mathrm{psi}$, and thermal cycled 98 times between 680 and $1500 \mathrm{~F}$ at various temperature differentials. 
TABLE 1. HYDROGEN-TO-ZIRCONIUM RATIO OF CORES FOR SPECIMENS PRESSURE BONDED AT 1700 F FOR 4-1/2 HR AT 10,000 PSI

\begin{tabular}{|c|c|c|c|}
\hline \multirow[b]{2}{*}{ Specimen } & \multirow[b]{2}{*}{ Remarks } & \multicolumn{2}{|c|}{ Hydrogen-to-Zirconium Ratio } \\
\hline & & Before Bonding & After Bonding \\
\hline $1700-1$ & Cu-Mo barrier layer & 1.66 & 1.56 \\
\hline $1700-3$ & $\mathrm{Cu}-\mathrm{Nb}$ barrier layer & 1.97 & 1.64 \\
\hline $1700-5$ & Mo barrier layer & 1.74 & 1.56 \\
\hline $1700-7$ & Nb barrier layer & 1.73 & 1.58 \\
\hline $1700-9$ & Type 304 stainless-clad specimen & 1.76 & 1.63 \\
\hline $1700-11$ & $\begin{array}{l}\text { Type } 304 \text { stainless-clad defective- } \\
\text { core specimen }\end{array}$ & 1.72 & 1.65 \\
\hline $1700-13$ & $\begin{array}{l}\text { Type } 304 \text { stainless-clad } \mathrm{ZrH}_{0 .} 86 \\
\text { specimen }\end{array}$ & 0.850 & 0.800 \\
\hline
\end{tabular}

TABLE 2. HYDROGEN-TO-ZIR CONIUM RA TIO OF CORES PRESSURE BONDED AT 1650 F FOR 4 HR AT 1800 F EOR 2 HR AT 10,000 PSI

\begin{tabular}{|c|c|c|c|}
\hline \multirow[b]{2}{*}{ Specimen } & \multirow[b]{2}{*}{ Remarks } & \multicolumn{2}{|c|}{ Hydrogen-to-Zirconium Ratio } \\
\hline & & Before Bonding & After Bonding \\
\hline $1800-1$ & Cu-Mo barrier layer & 1.84 & 1.59 \\
\hline $1800-3$ & $\mathrm{Cu}-\mathrm{Nb}$ barrier layer & 1.84 & 1.45 \\
\hline $1800-5$ & Mo barrier layer & 1.83 & 1. 48 \\
\hline $1800-8$ & No barxier layer & 1.80 & 1.34 \\
\hline $1800-9$ & Type 304 stainless-clad specimen & 1.81 & 1.54 \\
\hline $1800=11$ & $\begin{array}{l}\text { Type } 304 \text { stainless-clad defective- } \\
\text { core specimen }\end{array}$ & 1.81 & 1.45 \\
\hline $1800-13$ & $\begin{array}{l}\text { Type } 304 \text { stainless-clad } 2 \mathrm{rH} 0.86 \\
\text { specimen }\end{array}$ & 0.860 & 0.79 \\
\hline
\end{tabular}


TABLE 3. HYDROGEN-TO-ZIRCONIUM RATIO OF CORES PRESSURE BONDED AT 1800 F FOR 2 HR AND AT 1900 F FOR $2-1 / 2 \mathrm{HR}$ A T 10,000 PSI

\begin{tabular}{llcc}
\hline \hline Specimen & \multicolumn{1}{c}{ Remarks } & \multicolumn{2}{c}{ Hydrogen-to-Zirconium Ratio } \\
\hline $1900-2$ & Cu-Mo barrier layer & 1.82 & 1.47 \\
$1900-3$ & Cu-Nb barrier layer & 1.82 & 1.01 \\
$1900-7$ & Nb barrier layer & 1.85 & 1.29 \\
$1900-9$ & Type 304 stainless-clad specimen & 1.63 & 1.10 \\
$1900-11$ & $\begin{array}{c}\text { Type 304 stainless-clad defective- } \\
\text { core specimen }\end{array}$ & 1.53 & 1.10 \\
$1900-13$ & $\begin{array}{c}\text { Type 304 stainless-clad ZrHo.858 } \\
\text { specimen }\end{array}$ & 0.858 & 0.82 \\
\hline
\end{tabular}


bonding process. A bond is obtained between the hydride and stainless at a temperature below $1700 \mathrm{~F}$. The specimens are then heated to a higher temperature for a short period of time to improve the stainless-to-stainless bond. This high-temperature treatment can be carried out rapidly so that only the cladding and bond interface reach the maximum temperature. Induction heating or a rapid dip into a salt bath might be used in this technique.

General Conclusion From the Preliminary Bonding Studies

The preliminary bonding studies indicated that excellent bonding can be obtained by use of the gas pressure-bonding technique. The delta phase hydride does not appear to form brittle intermetallic compounds with stainless steel. As the hydrogen content is decreased to a level below $\mathrm{ZrH}_{1} .0$ the bonds become brittle; however, none of the hydride-to-stainless bonds was as brittle as the bond formed between zirconium and stainless steel.

The best bond was obtained when the delta-phase hydride was clad directly with the stainless. Since the proposed reactor design called for the use of nitrogen gas with a partial atmosphere of hydrogen, the molybdenum and niobium barrier materials were investigated primarily for bond improvement. In many other applications the use of molybdenum or niobium would be desired as barriers for the retention of hydrogen.

Thermal cycling did not appear to affect the bonds or produce fragmentation of the hydride.

The loss of hydrogen during pressure bonding was directly related to the temperature and time of bonding. The results also showed that it should be possible to obtain good over-all bonding by use of a two-step bonding operation with a relatively low loss of hydrogen. Several other techniques for bonding with little or no loss of hydrogen were previously discussed.

DEVELOPMENT STUDIES FOR DIRECT CLADDING OF SOLID DELTA-PHASE ZIRCONIUM HYDRIDE WITH STAINLESS STEEL

Further investigations into the direct cladding of delta-phase zirconium hydride with stainless steel appeared desirable on the basis of the conclusions drawn from the preliminary results obtained with the three sets of rod test specimens.

It was planned to concentrate on techniques for bonding and the evaluation of bond characteristics. There was an awareness of the hydrogen-retention problem and procurement of necessary equipment for the use of a partial hydrogen atmosphere in the high-pressure autoclave was initiated. 
Flat-plate and round specimens were prepared by pressure bonding. The use of zirconium hydride prepared by cold pressing of zirconium hydride powder was also investigated. It was felt that the pressed-powder product could be produced more readily and at a lower cost. The use of pressed-powder cores also eliminated the cracking problem encountered during the hydriding of relatively large pieces of delta-phase hydride. The two-step bonding operation was used in an effort to retain as much of the hydrogen as possible during the bonding operation. This was desirable because it has been clearly demonstrated that the hydride-stainless bond characteristics are a function of the hydrogen content.

The planned cladding development program was not completed. The work was terminated as a result of a change in the design of the GCRE from a hydride to a watermoderated system. A summary of the development work prior to termination is presented below.

Flat-Plate Specimens

Solid zirconium hydride cores were prepared for flat-plate specimens by restraining the zirconium hydride core in a stainless steel frame. This type of specimen was employed initially to further investigate direct cladding techniques. Two specimens prepared in the manner described with initial core compositions of $\mathrm{ZrH}_{1} .7$ and $\mathrm{ZrH}_{1.77}$ were pressure bonded in a two-step operation. The operation included pressure bonding at $1600 \mathrm{~F}$ for $4 \mathrm{hr}$ at $10,000 \mathrm{psi}$ followed by an additional $1-\mathrm{hr}$ treatment at $1900 \mathrm{~F}$ at $10,000 \mathrm{psi}$.

One of the specimens was sectioned for metallographic and peel-test studies. Microscopic examination of the specimen revealed intimate contact and good bonding between the stainless steel and the zirconium hydride on all surfaces.

The peel tests revealed good bonds between the stainless and stainless and the stainless and zirconium hydride.

Direct Cladding of Powder-Metallurgy Zirconium Hydride With Stainless Steel

The investigation of cladding green powdered zirconium hydride compacts was being conducted simultaneously with the cladding studies on solid zirconium hydride cores.

The initial investigations were conducted using powdered zirconium hydride compacts with an estimated $\mathrm{ZrH}_{1.6}$ composition. These cores were approximately 0.506 to $0.511 \mathrm{in}$. in diameter and 0.500 to $0.535 \mathrm{in}$. in length.

Two packs containing five powder-metallurgy zirconium hydride cores were as sembled into 0.518-in.-ID Type 304 stainless steel tubes with 0.517-in.-diameter by $0.250-i n$. - thick spacers between each core. The cores and cladding components were washed, assembled, evacuated, and sealed as previously described. 
The specimens were pressure bonded at 10,000 psi for $4 \mathrm{hr}$ at $1900 \mathrm{~F}$. Figure 19 shows one of the specimens after pressure bonding. The diameter of the cores was compressed 0.050 to $0.070 \mathrm{in}$. Most of this shrinkage was due to loss in hydrogen, causing the specimen to decrease in diameter as a result of the decreased density of the lower hydride.

The other specimen was sectioned to evaluate the bond. Microscopic examination of the specimen revealed intimate contact and good bonding with no noticeable diffusion at the bond interface between the stainless steel and the zirconium hydride powder. Figure 20 shows a typical section of the bond areas. The peel test revealed the powdered zirconium hydride-to-stainless bond to be good to excellent.

An as-received zirconium hydride core and a section from an as-bonded core were subjected to hydrogen analysis. The as-received zirconium hydride core had a $\mathrm{ZZrH}_{1.63}$ composition, while the bonded core had a $\mathrm{ZrH}_{1.31}$ composition. The results showed that a considerable amount of hydrogen was lost during pressure bonding at $1900 \mathrm{~F}$ for $4 \mathrm{hr}$ by a one-step pressure-bonding operation.

After trying various methods of compartmentalizing the powdered cores, such as the use of undersize spacers between the cores, it was decided to assemble one specimen with six cores without spacers between them. The cores and components were cleaned, assembled, evacuated, and sealed as before. The specimen was pressure bonded in a iwo-step operation at 10,000 psi for 3 hr at $1600 \mathrm{~F}$ followed by $1900 \mathrm{~F}$ for $1 \mathrm{hr}$. Figure 21 shows the pressure-bonded specimen before machining to final size. The diameter of the cores was compressed approximately $0.030 \mathrm{in}$. The specimen was machined to approximately 0.530 in. in diameter and both ends were exposed for examination of the specimen. The machined specimen is illustrated in Figure 22.

Microscopic examination and peel tests revealed a good bond between the powdered zirconium hydride core and the stainless steel cladding and the stainless steel end spacers.

A sample of the core taken from the specimen after pressure bonding was subm mitted for determination of hydrogen by the diffusion-extraction method. The sample had a $\mathrm{ZrH}_{1.43}$ composition.

A second zirconium hydride powder rod specimen was prepared in the same manner except that this specimen contained five 1-in.-diameter by 1 -in.-long cores. This specimen is shown in Figure 23 after being pressure bonded and in Figure 24 after being machined to a diameter of $1.010 \mathrm{in}$. One end of the specimen was exposed for examination of the core. Similar hydrogen-retention results were obtained with this specimen. 


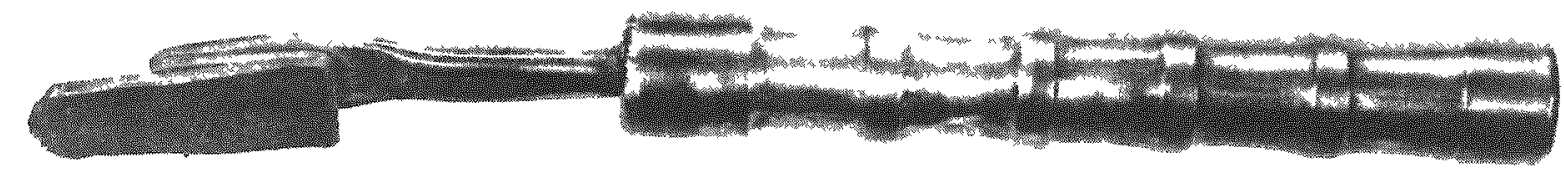

$1 \mathrm{X}$

RM7707

FIGURE 19. POWDERED ZIRCONIUM HYDRIDE CORE COMPARTMENTALIZED AND CLAD WITH TYPE 304 STAINLESS STEEL

Specimen 1900-1-3.

Type 304 stainless steel



Powdered zirconium hydride

FIGURE 20. POWDERED ZIRCONIUM HYDRIDE CORES CLAD WITH STAINLESS STEEL BY PRESSURE BONDING AT 10,000 PSI FOR 4 HR AT $1900 \mathrm{~F}$

Specimen 1900-1-4. 


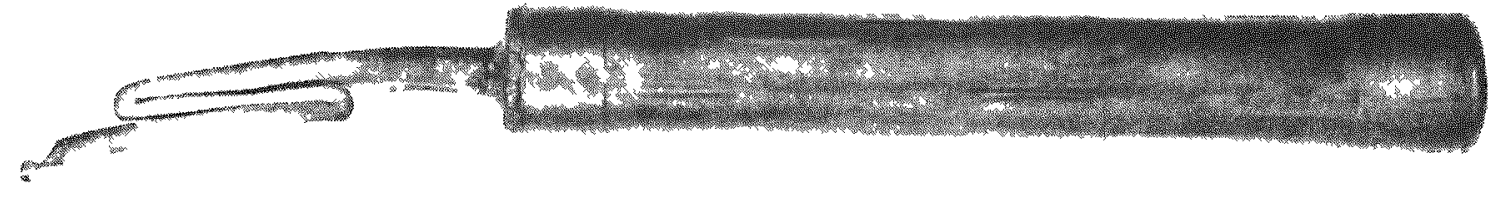

$1 \mathrm{X}$

RM7896

FIGURE 21. POWDERED ZIRCONIUM HYDRIDE CLAD SPECIMEN PRESSURE BONDED AT 10,000 PSI FOR 3 HR AT $1600 \mathrm{~F}$, FOLLOWED BY BONDING AT $1900 \mathrm{~F}$ FOR $1 \mathrm{HR}$

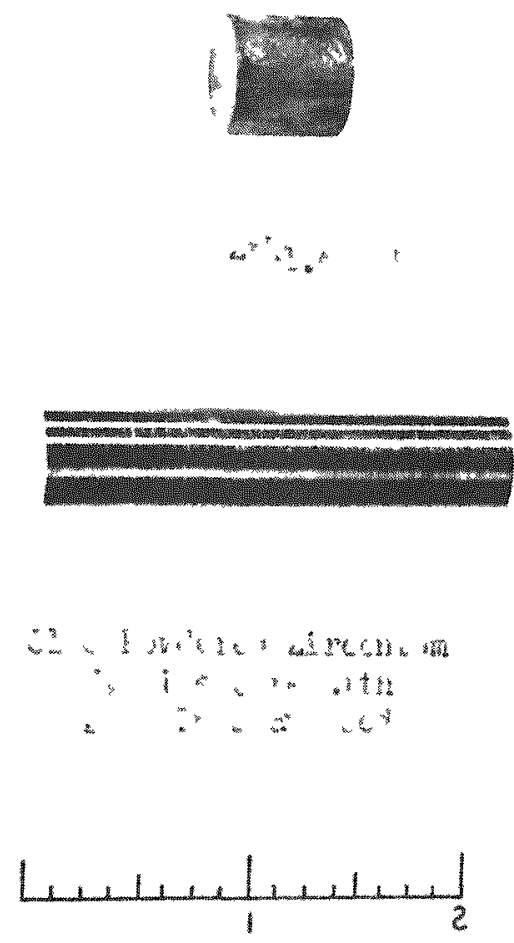

$1 \mathrm{X}$

RM8120

FIGURE 22. MACHINED POWDERED ZIRCONIUM HYDRIDE CLAD SPECIMEN Specimen 1900-4-1, an example of a powdered $\mathrm{ZrH}_{1} .6$ core. 


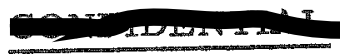

36

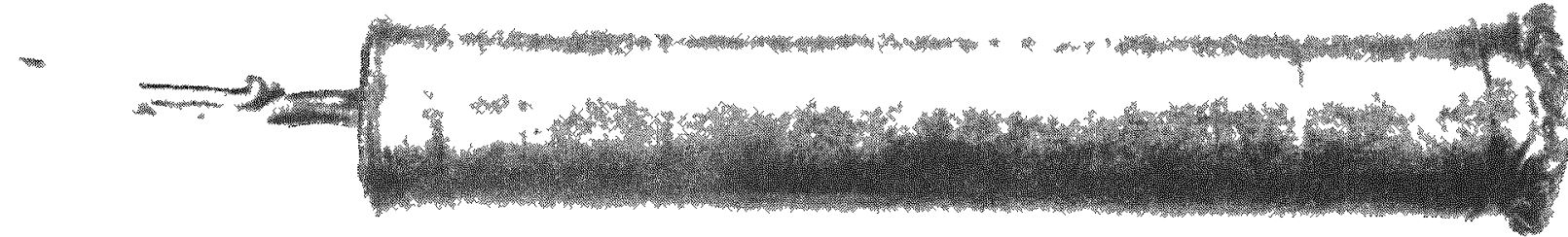

REDUCED 14\%

RM8103

FIGURE 23. POWDERED ZIRCONIUM HYDRIDE CLAD SPECIMEN WITH FIVE I-IN. DIAMETER CORES

Pressure bonded at 10,000 psi for $3 \mathrm{hr}$ at $1600 \mathrm{~F}$, followed by increasing the temperature to $1900 \mathrm{E}$ for $1 \mathrm{hr}$.
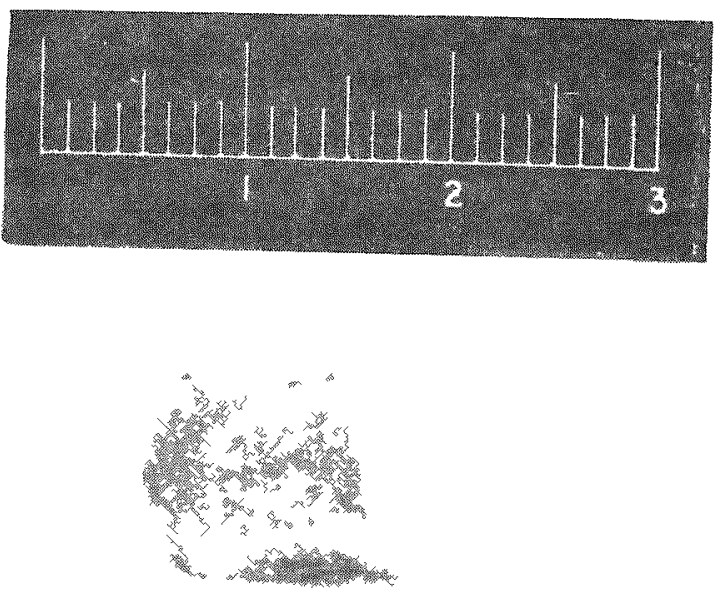

Powdered Zirconium Hydride Core

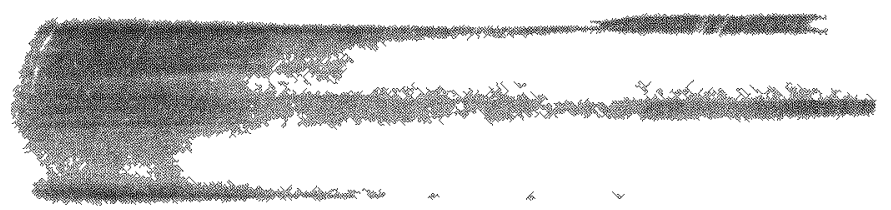

Clad Powdered Zirconium

Hydride Core With One

End Exposed

N41.993

FIGURE 24. POWDERED ZIRCONIUM HYDRIDE CORE AND A CIAD POWDERED ZIRCONIUM HYDRIDE SPECIMEN

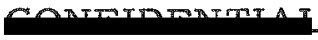

3.

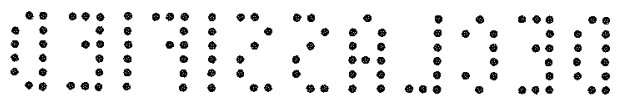




\section{SUMMARY AND CONCLUSIONS}

Delta-phase zirconium hydride can be clad with stainless steel by the use of a gas pressure-bonding technique. The components to be bonded are fabricated to final size, cleaned, and assembled into a stainless steel can. The as sembly is then evacuated, sealed, and subjected to a helium gas pressure of 10,000 psi at temperatures from 1650 to $1900 \mathrm{~F}$.

The best bonds were obtained by direct cladding of the hydride with stainless steel. The delta-phase hydride does not form the brittle intermetallic interface that is formed between zirconium and stainless. Since the proposed coolant was to embody a partial pressure of hydrogen, barrier materials for the retention of hydrogen were not investigated. The use of niobium and molybdenum barriers were investigated, but only for the purpose of bond improvement.

Hydride cores prepared by cold pressing of hydride powder were also clad with stainless steel by the gas pressure-bonding method. The bond between the green pressed hydride core and stainless steel was good with no apparent formation of a brittle intermetallic phase.

An appreciable amount of hydrogen was lost through dissociation of the hydride during pressure bonding at temperatures above $1700 \mathrm{~F}$. A two-step bonding operation consisting of a low-temperature treatment at $1650 \mathrm{~F}$ followed by a shorter hightemperature treatment at 1800 or $1900 \mathrm{~F}$ decreased the loss of hydrogen. For actual production cladding and control of hydrogen content, it is recommended to use a gas mixture of helium-hydrogen for pressure bonding. Equipment was being assembled for the use of a gas mixture; however, the program was terminated before the tests could be conducted.

SJP:ESH:CBB/apo/rr 